The University of New South Wales Australian School of Business

Australian School of Business Research Paper No. 2009ACTL08

Longevity Risk and the Econometric Analysis of Mortality Trends and Volatility

Carolyn Ndigwako Njenga \& Michael Sherris

This paper can be downloaded without charge from

The Social Science Research Network Electronic Paper Collection:

http://ssrn.com/abstract=1458084 


\title{
Longevity Risk and the Econometric Analysis of Mortality Trends and Volatility
}

\author{
Carolyn Ndigwako Njenga \\ Australian School of Business \\ Phd Student School of Actuarial Studies \\ University of New South Wales Sydney NSW 2052 \\ Australia \\ Email: ndigwako@hotmail.com \\ Michael Sherris \\ Australian School of Business \\ Professor and Head, School of Actuarial Studies \\ University of New South Wales Sydney NSW 2052 \\ Australia \\ Email: m.sherris@unsw.edu.au
}

Working Paper.

August 14, 2009

\begin{abstract}
Longevity risk and the modeling of trends and volatility for mortality improvement has attracted increased attention driven by ageing populations around the world and the expected financial implications. The original Lee-Carter model that was used for longevity risk assessment included a single improvement factor with differential impacts by age. Financial models that allow for risk pricing and risk management have attracted increasing attention along with multiple factor models. This paper investigates trends, including common trends through co-integration, and the factors driving the volatility of mortality using principal components analysis for a number of developed countries including Australia, England, Japan, Norway and USA. The results demonstrate the need for multiple factors for modeling mortality rates across all these countries. The basic structure of the Lee-Carter model can not adequately model the random variation and the full risk structure of mortality changes. Trends by country are found to be stochastic. Common trends and co-integrating relationships are found across ages highlighting the benefits from modeling mortality rates as a system in a Vector-Autoregressive (VAR) model and capturing long run equilibrium relationships in a Vector Error-Correction Model (VECM) framework.
\end{abstract}




\section{Introduction}

Longevity risk has been recognized as one of the significant risks impacting on the financing of ageing populations around the world. It has implications for insurance companies issuing life annuity and other products providing longevity insurance, pension funds as well as governments with social security pension obligations. Mortality rates have been declining globally at different rates and with volatilities varying by age-group and country (Tuljapurkar et al 2000). There has also been observed decreasing improvements with age and increasing trends in rates of change by age (Wong Fupuy-and Haberman 2004).

The Lee-Carter model (Lee and Carter 1992) has become a standard model for estimating and projecting mortality improvement. It has the benefit of modeling trends and volatilities by age and includes a common factor for the general level of improvement. Singular value decomposition is used to estimate the common factor and future projections are extrapolated based on trends in past data. The Lee-Carter model assumes a specific form of trend and of factors driving the underlying observed dynamics. It also assumes a common factor across ages. There have been proposed improvements to the model by including more factors, allowing for cohort effects, including more general error distributions and applying more efficient estimation techniques. Wills and Sherris (2008) provide a discussion of these model developments. Modeling mortality series across time for multiple ages and for many countries requires an understanding of the nature of trends in the data, common factors driving volatility or changes in mortality rates as well as an assessment of the number of significant factors to include in the model.

Econometric, and time series, analysis of data is based on an assessment of the nature of trends and volatility in the data and has been well developed in the application to modeling economic and financial time series (Juselius 2006, Pagan and Pesaran 2008 and Pfaff 2008). Trends may be either deterministic or stochastic and differentiating between these cases is critical to the modeling of the series. Unit-root tests, such as the Dickey-Fuller and Phillips-Perron tests, are used to determine if the historical series show evidence of stochastic trends (Pfaff 2008). For multiple series an analysis of the number of factors driving the volatility of the series allows a dimension reduction for the estimation of the series as well as providing valuable information about the factors driving changes in mortality. Econometric techniques also 
allow the modeling of multiple series and the estimation of long-run equilibrium relationships in the historical series as well as short term variations as the series move towards the long-run equilibrium. This can provide valuable insights into mortality changes across ages, across countries and across other factors such as sex.

This paper provides an assessment of longevity risk using econometric analysis of age-specific death rates in a number of developed countries including Japan and Australia from the Asia-Pacific region. The analysis considers the statistical evidence in the data in order to determine if models for longevity risk should assume trend or difference stationary processes and to understand if these vary across country. It also provides estimates of the number of factors driving the changes in the age-specific death rates for different countries and considers the extent to which these factors are common across the countries. Certain factors impacting changes to mortality rates would be expected to be common to certain age-groups, certain cohorts and the entire population, even though such changes may only be temporary (Pitacco 2007).

The investigation of mortality rates is based on population data obtained from the Human Mortality Database, University of California, Berkeley (USA) and Max Planck Institute for Demographic Research (Germany) for Australia, England and Wales, Japan, Norway and USA. These countries were selected because they provide a coverage of different parts of the world, are all developed countries with similar economic and social environments and generally expected to exhibit consistent mortality patterns (Tuljapurkar 2000).

The aim of the paper is to provide an analysis of trends and volatility of the historical longevity data across ages and for a number of countries expected to have experienced similar longevity improvements. There has been no previous econometric analysis of mortality for a range of countries investigating the nature of trends, number of factors driving volatility as well as applying cointegration models. McNown and Rogers (1989) apply univariate ARIMA time series models to mortality data but do not consider multivariate models. Recent developments in econometric modeling allow multivariate techniques to be applied.

The first section of the paper considers the econometric analysis of the trends in the data. Following that the results from a principal components 
analysis (PCA) for the number of factors that affect mortality across age and country are discussed. Cointegration as a modeling approach is reviewed and applied to assess cross country common trends and common trends by age for the Australian data.

\section{Modeling Mortality Trends}

Average mortality rates have been declining globally. Figure 1 represents average rates of mortality across the countries in this study for all the years of data that are available. It shows this trend and it is noticed that for the countries whose data dates back to the 19th century, the decline in mortality rates has been very significant over the past 50-80 years. Lee (2000) attributes the improvements in life expectancies to greater reductions in mortality rates at lower ages rather than at higher ages. Figure 2 shows this clearly for the Australian data.
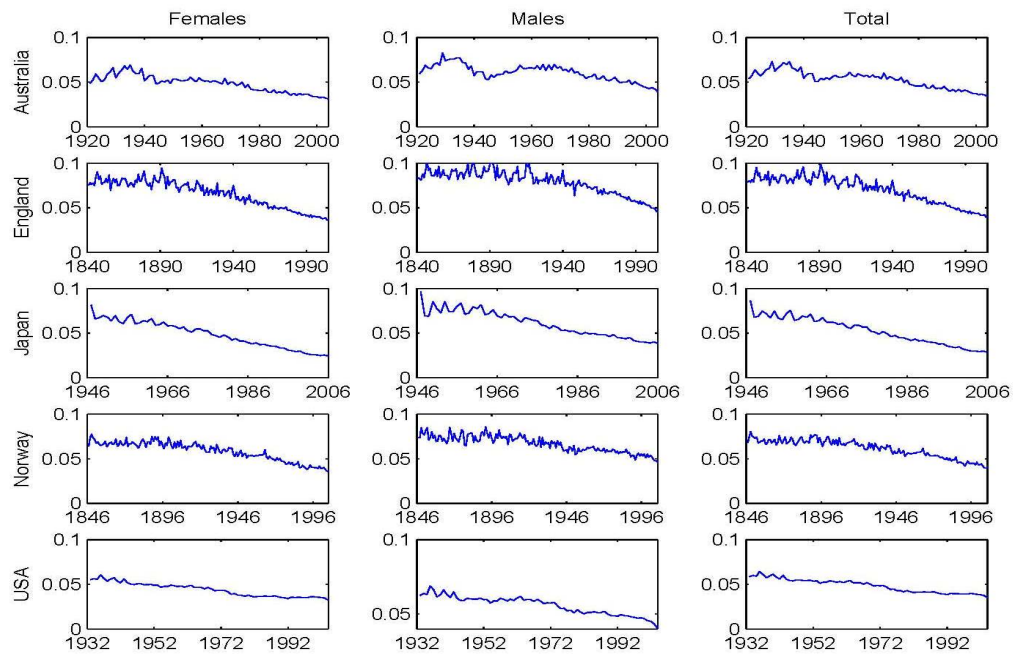

Figure 1: Average Death Rates for Five Countries in the Study

To show the overall level of mortality for each country a simple average of the population mortality rates was used in Figure 1. However, in order to compare across countries standardized mortality rates are a better indicator of trends for comparison. For this purpose rates were standardised using the World Health Organization (WHO) World standard population given in Table 1.

The time series plots of the female and male standardized population 

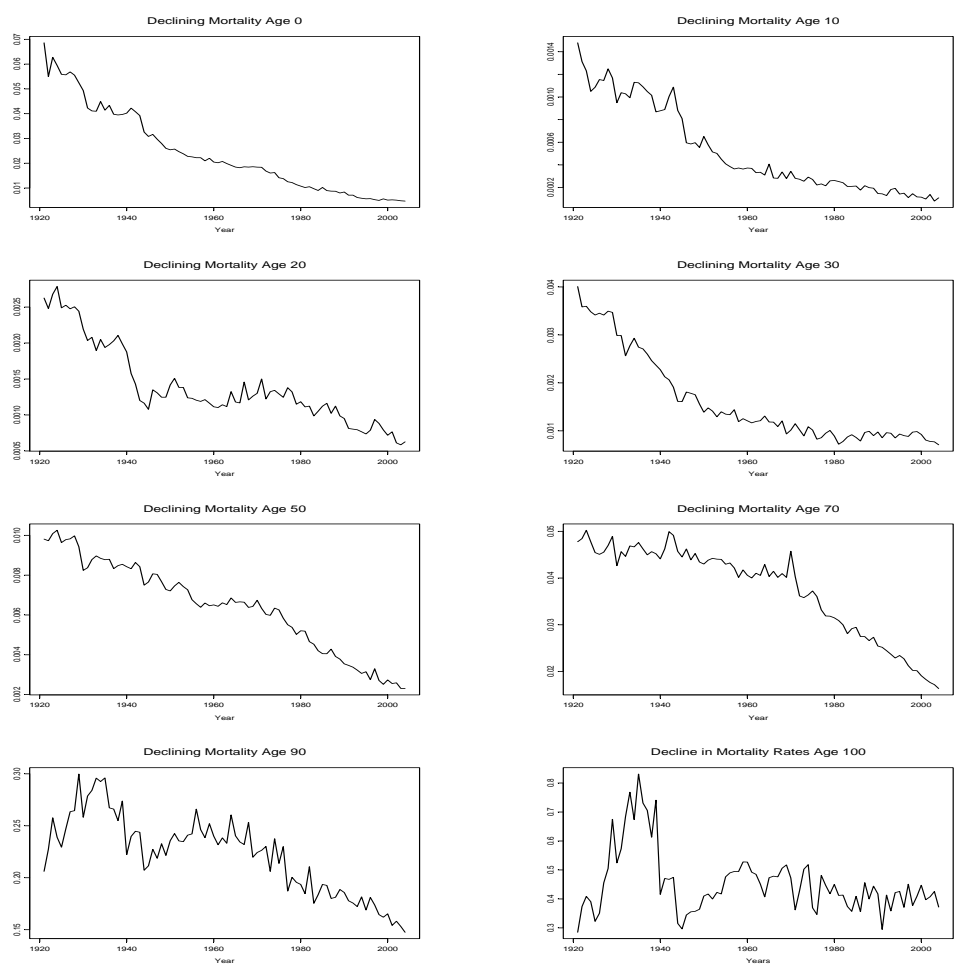

Figure 2: Age Specific Death Rates at Different Ages (Australia)

\begin{tabular}{c|c}
\hline Age Group & World Average \\
\hline $0-4$ & 8.86 \\
$5-9$ & 8.69 \\
$10-14$ & 8.6 \\
$15-19$ & 8.47 \\
$20-24$ & 8.22 \\
$25-29$ & 7.93 \\
$30-34$ & 7.61 \\
$35-39$ & 7.15 \\
$40-44$ & 6.59 \\
$45-49$ & 6.04 \\
$50-54$ & 5.37 \\
$55-59$ & 4.55 \\
$60-64$ & 3.72 \\
$65-69$ & 2.96 \\
$70-74$ & 2.21 \\
$75-79$ & 1.52 \\
$80-84$ & 0.91 \\
$85-89$ & 0.44 \\
$90-94$ & 0.15 \\
$95-99$ & 0.04 \\
$100+$ & 0.005 \\
\hline
\end{tabular}

Table 1: WHO World Standardized Population 


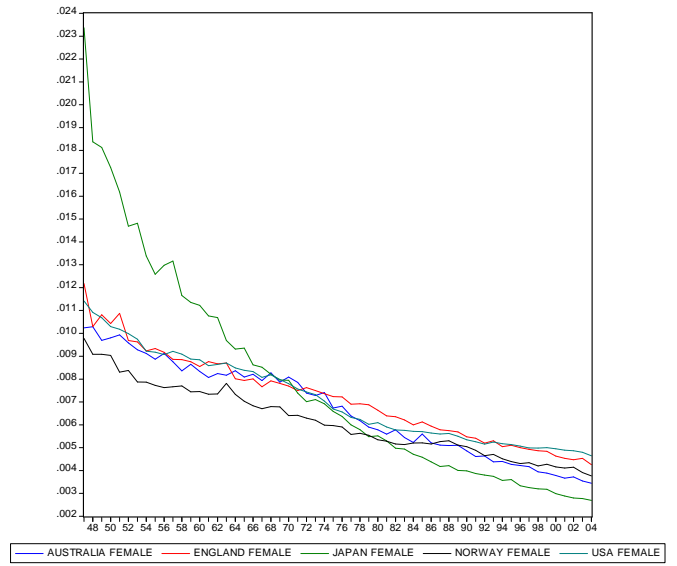

Figure 3: Standardized Female Mortality Rates

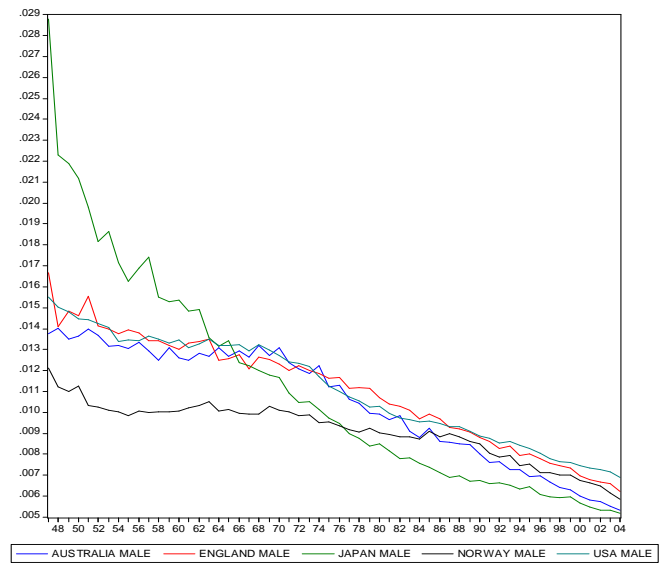

Figure 4: Standardized Male Mortality Rates

mortality rates for common time periods, $\mathbf{m}_{t}$ are shown in Figures 3 and 4 respectively. These figures show the possibility that mortality improvement across these countries, for both females and males, has common trends. They also show significant variability in the trends.

When modeling mortality rates by age across time a system of equations is often used for discrete ages. The trends by age are captured by an age based model such as the Lee-Carter model. Mortality rates exhibit trends across time for a given age. At any given time there are trends across age. However as individuals age trends occur for a cohort of individuals born in the same year. Trends for a cohort reflect changes in time as well as changes in age. The mortality rates of most interest are the cohort rates since these are used to project future mortality based on each cohort year of birth. These are a combination of trends across time and by age.

To examine trends in mortality, two types of differences can be considered:

$$
\begin{aligned}
& \Delta_{h} m(x, t)=m(x, t)-m(x, t-1) \quad \text { Horizontal Differences } \\
& \Delta_{d} m(x, t)=m(x, t)-m(x-1, t-1) \quad \text { Diagonal Differences }
\end{aligned}
$$

$\Delta_{h} \mathbf{m}(x, t)$ shows how mortality rates change over time for a given age $x$. They reflect time trends only for any given age. When all ages are considered they allow common trends to be identified across time for levels of mortality.

$$
\boldsymbol{\Delta}_{\mathbf{h}} \mathbf{m}(\mathbf{x}, \mathbf{t})=\left(\begin{array}{cccc}
m\left(x_{0}, t_{2}\right) & m\left(x_{0}, t_{3}\right) & \ldots & m\left(x_{0}, T\right) \\
m\left(x_{1}, t_{2}\right) & m\left(x_{1}, t_{3}\right) & \ldots & m\left(x_{1}, T\right) \\
\vdots & \vdots & \ddots & \vdots \\
m\left(x_{N}, t_{2}\right) & m\left(x_{N}, t_{3}\right) & \ldots & m\left(x_{N}, T\right)
\end{array}\right)-\left(\begin{array}{cccc}
m\left(x_{0}, t_{1}\right) & m\left(x_{0}, t_{2}\right) & \ldots & m\left(x_{0}, T-1\right) \\
m\left(x_{1}, t_{1}\right) & m\left(x_{1}, t_{2}\right) & \ldots & m\left(x_{1}, T-1\right) \\
\vdots & \vdots & \ddots & \vdots \\
m\left(x_{N}, t_{1}\right) & m\left(x_{N}, t_{2}\right) & \ldots & m\left(x_{N}, T-1\right)
\end{array}\right)
$$




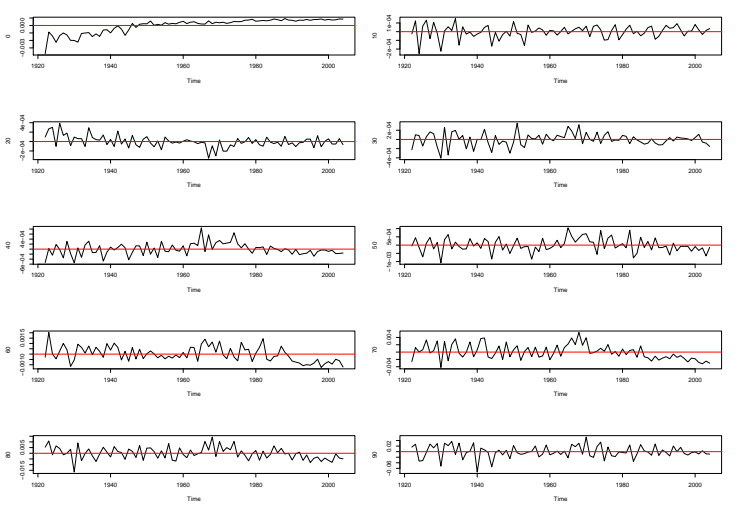

Figure 5: Time ordered errors for Diagonal Differences
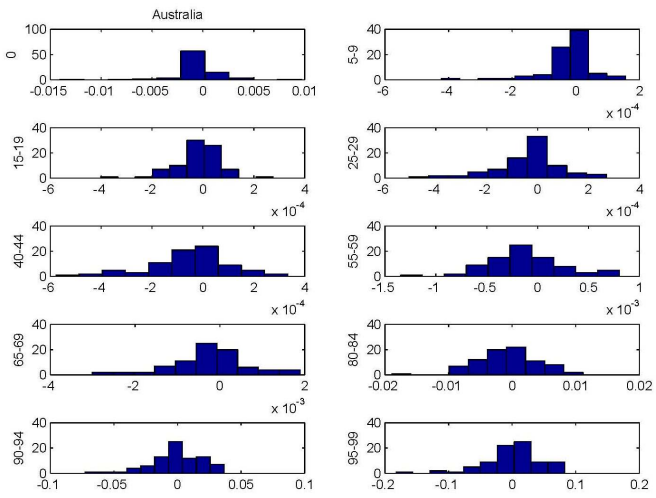

$\Delta_{d} \mathbf{m}(x, t)$ shows how mortality for a given age cohort changes from one year to the next. These are mortality changes for a set of individuals born in the same year and who experience common factors through time. The changes in the cohort rates include effects from age and from time.

$\boldsymbol{\Delta}_{\mathbf{d}} \mathbf{m}(\mathbf{x}, \mathbf{t})=\left(\begin{array}{cccc}m\left(x_{1}, t_{2}\right) & m\left(x_{1}, t_{3}\right) & \ldots & m\left(x_{1}, T\right) \\ m\left(x_{2}, t_{2}\right) & m\left(x_{2}, t_{3}\right) & \ldots & m\left(x_{2}, T\right) \\ \vdots & \vdots & \ddots & \\ m\left(x_{N}, t_{2}\right) & m\left(x_{N}, t_{3}\right) & \ldots & m\left(x_{N}, T\right)\end{array}\right)-\left(\begin{array}{cccc}m\left(x_{0}, t_{1}\right) & m\left(x_{0}, t_{2}\right) & \ldots & m\left(x_{0}, T-1\right) \\ m\left(x_{1}, t_{1}\right) & m\left(x_{1}, t_{2}\right) & \ldots & m\left(x_{1}, T-1\right) \\ \vdots & \vdots & \ddots & \\ m\left(x_{N-1}, t_{1}\right) & m\left(x_{N-1}, t_{2}\right) & \ldots & m\left(x_{N-1}, T-1\right)\end{array}\right)$

Figure 5 shows the diagonal or cohort differences and Figure 6 shows the period differences for the Australian data. The changes in cohort mortality in Figure 5 vary by age although they generally fluctuate around a constant level. Modeling mortality rates by cohort requires an allowance for trends varying by age but otherwise the graphs are not inconsistent with stationary differences in the mortality rates. The changes in the mortality rates by fixed age over time that are given in Figure 6 indicate that the differences of the age specific mortality rates appear stationary with an approximately normal distribution from the histograms at various ages. Formal modeling and testing of model assumptions is required to confirm these observations.

The stationarity or non-stationarity of a time series is very important in developing an appropriate model. A mortality rate series may have a deterministic trend around which the series fluctuates and the trend-stationary time series has the form

$$
y_{t}=\mu+\phi y_{t-1}+u_{t}
$$


with $|\phi|<1$. After fitting the trend the model errors would then be stationary.

Alternatively the mortality rates may have a stochastic trend and the rate of change in mortality would be stationary with drift or trend. The random walk with drift takes the form

$$
y_{t}=\mu+y_{t-1}+u_{t}
$$

Using the backshift operator $B$ such that $B y_{t}=y_{t-1}$ the difference operator is $\Delta y_{t}=(1-B) y_{t}=y_{t}-y_{t-1}$. The random walk with drift can be written as:

$$
\begin{aligned}
y_{t} & =\mu+y_{t-1}+u_{t} \\
y_{t}-y_{t-1} & =\mu+y_{t-1}-y_{t-1}+u_{t} \\
(1-B) y_{t} & =\mu+u_{t}
\end{aligned}
$$

$\Delta y_{t}$ is a stationary variable and stationarity has been induced by differencing once. The characteristic equation is $(1-x)=0$ and has a root $x=1$, hence $y_{t}$ is referred to as having a unit root.

Differentiating between these two situations is important in fitting mortality trends since the nature of the trends and shocks will have quite different implications for modeling future rates. To illustrate the importance of this consider a stationary $A R(1)$ mean adjusted series $y_{t}$ as:

$$
y_{t}=\phi y_{t-1}+u_{t}
$$

where $u_{t}$ is a random mean zero shock. This can be written in terms of lagged values as:

$$
\begin{aligned}
y_{t} & =\phi\left(\phi y_{t-2}+u_{t-1}\right)+u_{t} \\
& =\phi^{2} y_{t-2}+\phi u_{t-1}+u_{t} \\
& =\phi^{2}\left(\phi y_{t-3}+u_{t-2}\right)+\phi u_{t-1}+u_{t} \\
& =\phi^{3} y_{t-3}+\phi^{2} u_{t-2}+\phi u_{t-1}+u_{t}
\end{aligned}
$$

which becomes

$$
y_{t}=\phi^{T+1} y_{t-(T+1)}+\phi^{T} u_{t-T}+\phi^{T-1} u_{T-1}+\ldots+\phi^{2} u_{t-1}+\phi u_{t-1}+u_{t}
$$


If $\phi<1$ then as $T \rightarrow \infty$ the effect of the past random shocks gradually diminishes since $\lim _{T \rightarrow \infty} \phi^{T}=0$, which implies $y_{t}$ is stationary.

If $\phi=1$ then the series has a unit root and as $T \rightarrow \infty$ the effect of the shocks persist since $\lim _{T \rightarrow \infty} \phi^{T}=1$ and they accumulate as stochastic trends in the series:

$$
y_{t}=y_{0}+\sum_{t=0}^{\infty} u_{t}
$$

For the trend stationary model it is necessary to estimate the trend as part of a stationary model using the levels of the series. In the case of the series with the unit root it is necessary to take differences and to model the differences as a stationary series. For the difference stationary series, the series is said to be integrated of order 1 or I(1). Unit root tests are critical in determining the model assumptions. For difference stationary models, shocks to the series have permanent effects and the variance increases with time. With a trend stationary model the shocks around the trend have constant variance and shocks are transitory.

\section{Lee and Carter 1992}

Lee and Carter (1992) model the age-specific death rates as a time series using:

$$
\ln m(x, t)=\alpha(x)+\beta(x) k(t)+\epsilon(x, t)
$$

where $\alpha(x)$ is the age pattern of mortality averaged over time, $\beta(x)$ are the age specific deviations from the time factor $k(t)$ and $\epsilon(x, t)$ are short term fluctuations assumed to be normally distributed in the classical Lee-Carter Model. Trends are modeled with a random factor $k(t)$ determining common time trends. The age-specific reaction to the random time trend, $b(x)$, is fixed over time and only varies by age. The Lee-Carter model mortality index $k(t)$ is usually modeled with a random walk or an $A R(1)$ process.

The Lee-Carter (1992) model can be re-written in the following form for age $x$ with a random walk assumption for trends given by $k(t)=\mu+k(t-$ 
1) $+\xi(t)$ :

$$
\begin{aligned}
& \qquad \begin{aligned}
\ln m(t) & =a+b k(t)+\epsilon(t) \\
\ln m(t-1) & =a+b k(t-1)+\epsilon(t-1) \\
\ln m(t)-\ln m(t-1)=b(\mu+\xi(t))+\epsilon(t)-\epsilon(t-1) & \\
\ln m(t) & =b \mu+\ln m(t-1)+\epsilon^{*}(t) \\
\text { where } \epsilon^{*}(t) & =b \xi(t)+\epsilon(t)-\epsilon(t-1)
\end{aligned}
\end{aligned}
$$

Only in this case, with the random common mortality trend for the log of the rates assumed to be a random walk, will the Lee-Carter (1992) model correspond to a difference stationary model. Volatility is modeled with a single common factor $k(t)$ and independent noise $\epsilon(x, t)$ (Ahlo 2000; Lee 2000).

The results of fitting the Lee-Carter model to the mortality data from the countries in this study are presented in Figure 7. In the first column the mortality trends from the Lee-Carter model are given. The patterns across the countries vary and, although there is evidence of a common downward trend reflecting mortality improvement across these countries, an examination of the second column showing the model error structure indicates that there are trends not captured by the Lee-Carter model. This visual display of the Lee-Carter model results for these countries indicates the need to assess if the mortality improvement trends are stochastic, whether there are common trends across countries and also how many factors are required to explain the variation in mortality rates.

\section{Unit Root Tests}

To determine if the series are trend or difference stationary there are econometric tests that have been developed in the econometric and financial literature since this is a common feature in many economic and financial series. There exist various statistical tests for unit roots including the Dickey-Fuller (Dickey and Fuller 1979) and the Augmented Dickey Fuller Test as well as the Phillips-Perron test (Phillips and Perron 1988). These tests consider the null hypothesis that the series is non-stationary and require evidence to reject the null hypothesis.

The assumptions for the standard Dickey Fuller test is to write the series 
Australia
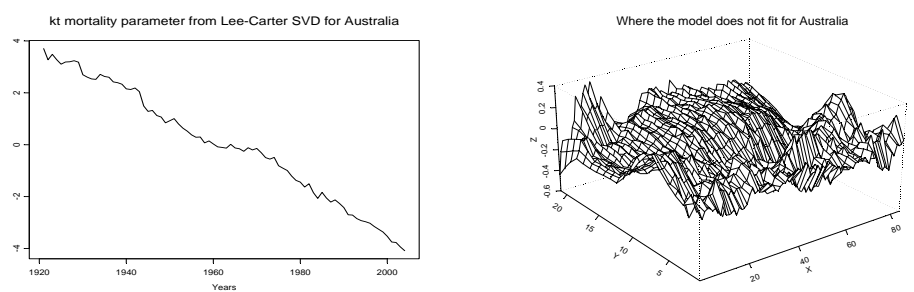

Japan
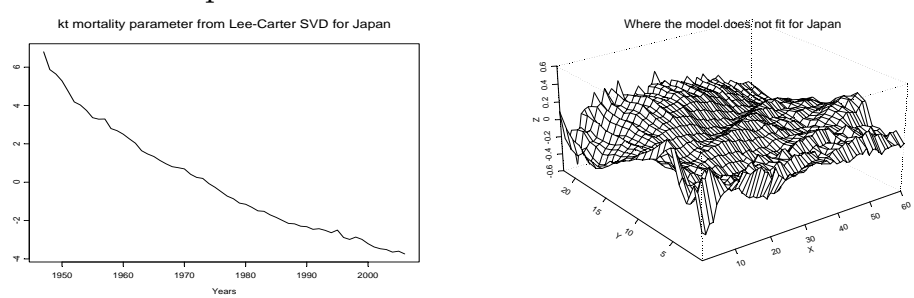

England
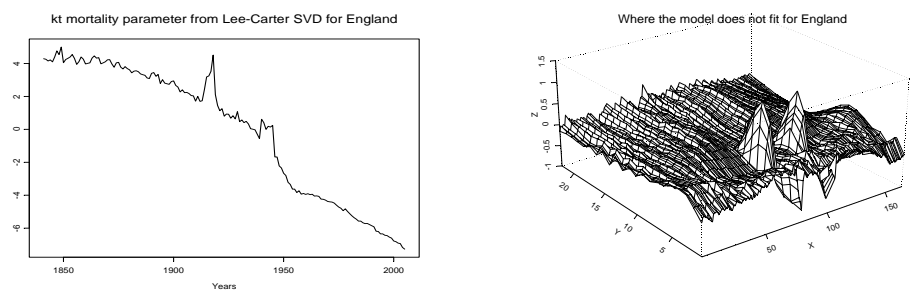

Norway
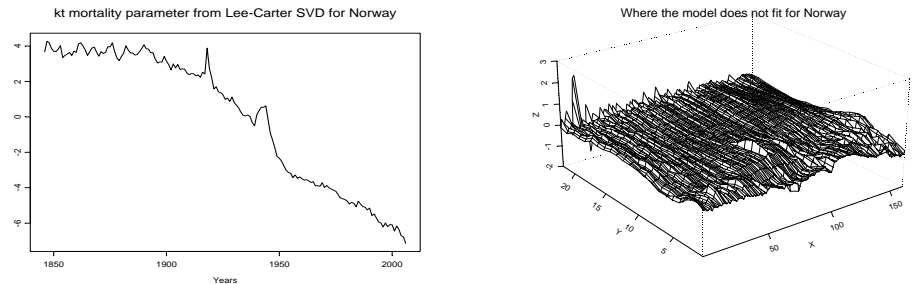

USA
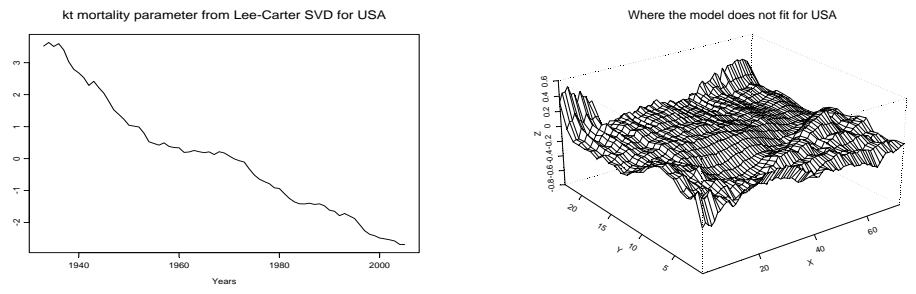

Figure 7: Lee-Carter Model - Trends and model errors 
with a deterministic linear trend as:

$$
y_{t}=\phi y_{t-1}+\alpha+\beta t+u_{t}
$$

which after subtracting $y_{t-1}$ from each side becomes:

$$
\Delta y_{t}=(\phi-1) y_{t-1}+\alpha+\beta t+u_{t}
$$

The null hypothesis is that the coefficient on $y_{t-1}$ is zero. If this null is rejected then the series is modeled as stationary but if it is not rejected then the series is modeled as difference stationary. Non-standard test statistics are required under the null hypothesis.

The standard Dickey Fuller test is only valid if the white noise $u_{t}$ terms are not autocorrelated. This situation is handled in the augmented Dickey Fuller model by including a number of lags, $p$, for $y_{t}$ and the model becomes:

$$
\Delta y_{t}=\psi y_{t-1}+\sum_{i=1}^{p} \alpha_{i} \Delta y_{t-i}+u_{t} \quad, \quad \psi=\phi-1
$$

where the number of lags, $p$ are usually selected either based on the frequency of the data, where for monthly data 12 lags would be used or for quarterly data 4 lags, or based on an information criterion to select the number of lags that minimizes the value of the information criterion.

It is important to select the number of lags with care since including too few lags will not remove all the autocorrelation while including too many lags reduces the power of the test. The mortality rate time series were found to be sensitive to the lag length.

Phillips and Perron (1988) and Perron (1988) introduce a test that allows for autocorrelated residuals. In the Dickey Fuller Test $u_{t}$ are assumed to be independent and identically distributed while in the Phillips-Perron test $u_{t}$ are assumed to be serially correlated. The Phillips-Perron test is usually more powerful than the Augmented Dickey-Fuller test but it is also more sensitive to miss-specification of the order of the lag of its autoregressive and moving average components.

These tests have been known to have low power if the process is stationary but with root close to 1 . For these series it is difficult to determine if they have long run trends or are random walks with stochastic trends. Tests such as the Kwiatkowski, Phillips, Schmidt, and Shin (KPSS, 1992) test are then 
used since they assume stationarity as the null hypothesis $\left(H_{0}: y_{t} \sim I(0)\right)$ and require evidence of non-stationarity. The joint use of unit root tests and stationarity tests places checks on the standard unit root tests and provides a stronger basis for determining if trends are deterministic or stochastic.

There are four possible outcomes of this analysis using both unit root tests along with stationarity tests:

1. Unit root test - Reject $H_{0}$; Stationarity test - Do not reject $H_{0}$ (Stationary)

2. Unit root test - Do not reject $H_{0}$; Stationarity test - Reject $H_{0}$ (Nonstationary)

3. Unit root test - Reject $H_{0}$; Stationarity test - Reject $H_{0}$ (Inconclusive)

4. Unit root test - Do not reject $H_{0}$; Stationarity test - Do not reject $H_{0}$ (Inconclusive)

Unit root and stationarity tests were performed on the mortality rate time series for the period from 1963-2004. The period from 1963-2004 is considered because there is a very drastic improvement in mortality for Japan between 1947 and 1962 which may distort the effects of common trends. Differences are considered for fixed ages across time in order to model time trends. The unit root tests and stationarity test were conducted in Eviews. The ADF test was conducted with Schwartz Information Criterion used to determine the appropriate lag length, $p$. The Phillips and Perron test was also conducted. Table 2 and Table 3 present the ADF and PP test results as well as the stationarity tests for females and males respectively for the countries in this study. The unit root tests confirm that the population level mortality rates are all non-stationary and are integrated of order one, I(1). For both the males and the females, the $\mathrm{ADF}$ and $\mathrm{PP}$ test $\mathrm{p}$-values do not reject the null hypothesis of the existence of a unit root for the country mortality time series but they all reject this null hypothesis for the first differences. The test statistic is greater than the critical value for the country mortality series but is smaller than the critical value for the differenced mortality series, hence the tests confirm that the series are integrated of order one for both the males and the females. The country level tests for both males and females for the KPSS tests and these confirm the conclusion that differences of the mortality rates at the country level are stationary and not the levels. 


\begin{tabular}{|c|c|c|c|c|c|c|}
\hline Females & & & & & & \\
\hline \multirow[t]{2}{*}{ ADF Test } & \multicolumn{6}{|l|}{ P-Values } \\
\hline & Constant & Lags & DW Stat. & Constant, Trend & Lags & DW Stat. \\
\hline Australia & 0.796 & 2 & 1.946 & $0.9312^{(1)}$ & 2 & 1.954 \\
\hline$\Delta$ Australia & 0 & 0 & 2.116 & 0 & 1 & 1.946 \\
\hline England & 0.9323 & 2 & 1.974 & 0.005 & 0 & 1.595 \\
\hline$\Delta$ England & 0 & 0 & 2.567 & 0 & 1 & 1.977 \\
\hline Japan & 0 & 2 & 1.778 & $0.5992^{(1)}$ & 2 & 1.778 \\
\hline$\Delta$ Japan & 0 & 0 & 1.835 & 0 & 0 & 2.156 \\
\hline Norway & 0.128 & 0 & 1.940 & 0.0068 & 0 & 1.933 \\
\hline$\Delta$ Norway & 0 & 0 & 2.204 & 0 & 0 & 2.167 \\
\hline USA & 0.0335 & 0 & 2.123 & $0.9286^{(1)}$ & 0 & 2.111 \\
\hline$\Delta$ USA & 0 & 0 & 2.046 & 0 & 0 & 1.894 \\
\hline \multirow[t]{2}{*}{ Phillips-Perron Test } & \multicolumn{6}{|l|}{ P-Values } \\
\hline & Constant & Bandwidth & DW Stat. & Constant, Trend & Bandwidth & DW Stat. \\
\hline Australia & 0.8998 & 1 & 2.983 & $0.1875^{(1)}$ & 4 & 2.504 \\
\hline$\Delta$ Australia & 0 & 4 & 2.116 & 0 & 4 & 2.135 \\
\hline England & 0.6655 & 0 & 2.364 & 0.002 & 4 & 1.595 \\
\hline$\Delta$ England & 0 & 5 & 2.567 & 0 & 5 & 2.564 \\
\hline Japan & 0 & 8 & 2.965 & $0.897^{(1)}$ & 3 & 2.889 \\
\hline$\Delta$ Japan & 0 & 4 & 1.835 & 0 & 26 & 2.156 \\
\hline Norway & 0.1253 & 3 & 1.940 & 0.0089 & 4 & 1.933 \\
\hline$\Delta$ Norway & 0 & 2 & 2.204 & 0 & 1 & 2.167 \\
\hline USA & 0.0334 & 2 & 2.123 & $0.9281^{(1)}$ & 2 & 2.112 \\
\hline$\Delta \mathrm{USA}$ & 0 & 3 & 2.046 & 0 & 2 & 1.894 \\
\hline \multirow[t]{2}{*}{ KPSS Test } & \multicolumn{3}{|l|}{ Test Stat. } & \multicolumn{3}{|l|}{ Test Stat. } \\
\hline & Constant & Bandwidth & DW Stat. & Constant, Trend & Bandwidth & DW Stat. \\
\hline Australia & 0.789 & 5 & 0.024 & 0.145 & 5 & 0.654 \\
\hline$\Delta$ Australia & 0.110 & 1 & 2.997 & 0.104 & 1 & 2.998 \\
\hline England & 0.813 & 5 & 0.024 & 0.117 & 4 & 1.319 \\
\hline$\Delta$ England & 0.110 & 1 & 2.317 & 0.047 & 1 & 2.378 \\
\hline Japan & 0.790 & 5 & 0.013 & 0.216 & 5 & 0.136 \\
\hline$\Delta$ Japan & 0.812 & 4 & 2.408 & 0.101 & 8 & 2.969 \\
\hline Norway & 0.805 & 5 & 0.026 & 0.172 & 4 & 0.393 \\
\hline$\Delta$ Norway & 0.315 & 3 & 1.773 & 0.125 & 2 & 1.895 \\
\hline USA & 0.761 & 5 & 0.013 & 0.200 & 5 & 0.077 \\
\hline \multirow[t]{2}{*}{$\Delta \mathrm{USA}$} & 0.514 & 4 & 1.765 & 0.097 & 1 & 2.145 \\
\hline & Critical Val. & & & Critical Val. & & \\
\hline $1 \%$ & 0.739 & & $1 \%$ & 0.216 & & \\
\hline $5 \%$ & 0.463 & & $5 \%$ & 0.146 & & \\
\hline $10 \%$ & 0.347 & & $10 \%$ & 0.119 & & \\
\hline
\end{tabular}

Table 2: Unit Root and Stationarity Tests on Female Standardized Mortality Rates 1963-2004 (1) Significant Trend in Unit Root Test 


\begin{tabular}{|c|c|c|c|c|c|c|}
\hline Males & & & & & & \\
\hline \multirow[t]{2}{*}{ ADF Test } & \multicolumn{6}{|l|}{ P-Values } \\
\hline & Constant & Lags & DW Stat. & Constant, Trend & Lags & DW Stat. \\
\hline Australia & 0.9809 & 1 & 1.952 & 0.2383 & 1 & 1.858 \\
\hline$\Delta$ Australia & 0 & 0 & 1.947 & 0 & 0 & 1.951 \\
\hline England & 0.998 & 2 & 1.973 & 0.0345 & 0 & 1.833 \\
\hline$\Delta$ England & 0 & 1 & 1.861 & 0 & 1 & 1.994 \\
\hline Japan & 0.0129 & 1 & 1.988 & $0.9374^{(1)}$ & 1 & 1.984 \\
\hline$\Delta$ Japan & 0 & 0 & 1.809 & 0 & 0 & 2.002 \\
\hline Norway & 0.9999 & 1 & 1.887 & $0.9275^{(1)}$ & 1 & 1.894 \\
\hline$\Delta$ Norway & 0 & 0 & 1.759 & 0 & 0 & 1.900 \\
\hline USA & 0.8311 & 0 & 2.008 & $0.8487^{(1)}$ & 0 & 1.903 \\
\hline$\Delta$ USA & 0 & 0 & 1.89 & 0 & 0 & 1.883 \\
\hline \multirow[t]{2}{*}{ Phillips-Perron Test } & \multicolumn{6}{|l|}{ P-Values } \\
\hline & Constant & Bandwidth & DW Stat. & Constant, Trend & Bandwidth & DW Stat. \\
\hline Australia & 0.9927 & 17 & 2.999 & 0.005 & 1 & 2.430 \\
\hline$\Delta$ Australia & 0 & 2 & 1.947 & 0 & 1 & 1.951 \\
\hline England & 0.9558 & 2 & 2.562 & 0.0185 & 4 & 1.833 \\
\hline$\Delta$ England & 0 & 2 & 2.517 & 0 & 2 & 2.644 \\
\hline Japan & 0.002 & 10 & 2.865 & $0.9217^{(1)}$ & 4 & 2.786 \\
\hline$\Delta$ Japan & 0 & 3 & 1.809 & 0 & 10 & 2.002 \\
\hline Norway & 0.9985 & 1 & 2.615 & $0.9326^{(1)}$ & 2 & 2.382 \\
\hline$\Delta$ Norway & 0 & 3 & 1.760 & 0 & 2 & 1.900 \\
\hline USA & 0.8319 & 2 & 2.008 & $0.7899^{(1)}$ & 3 & 1.903 \\
\hline$\Delta \mathrm{USA}$ & 0 & 2 & 1.890 & 0 & 2 & 1.883 \\
\hline \multirow[t]{2}{*}{ KPSS Test } & \multicolumn{3}{|l|}{ Test Stat. } & \multicolumn{3}{|l|}{ Test Stat. } \\
\hline & Constant & Bandwidth & DW Stat. & Constant, Trend & Bandwidth & DW Stat. \\
\hline Australia & 0.795 & 5 & 0.022 & 0.083 & 4 & 0.938 \\
\hline$\Delta$ Australia & 0.234 & 15 & 2.987 & 0.201 & 20 & 3.021 \\
\hline England & 0.809 & 5 & 0.022 & 0.147 & 5 & 1.072 \\
\hline$\Delta$ England & 0.074 & 2 & 2.572 & 0.060 & 2 & 2.574 \\
\hline Japan & 0.780 & 5 & 0.015 & 0.211 & 5 & 0.145 \\
\hline$\Delta$ Japan & 0.749 & 3 & 2.512 & 0.108 & 9 & 2.877 \\
\hline Norway & 0.785 & 5 & 0.031 & 0.175 & 5 & 0.354 \\
\hline$\Delta$ Norway & 0.312 & 1 & 2.502 & 0.077 & 1 & 2.605 \\
\hline USA & 0.793 & 5 & 0.019 & 0.150 & 5 & 0.225 \\
\hline \multirow[t]{2}{*}{$\Delta$ USA } & 0.131 & 2 & 1.999 & 0.087 & 2 & 2.012 \\
\hline & Critical Val. & & & Critical Val. & & \\
\hline $1 \%$ & 0.739 & & $1 \%$ & 0.216 & & \\
\hline $5 \%$ & 0.463 & & $5 \%$ & 0.146 & & \\
\hline $10 \%$ & 0.347 & & $10 \%$ & 0.119 & & \\
\hline
\end{tabular}

Table 3: Unit Root and Stationarity Tests on Male Standardised Mortality Rates 1963-2004 (1) Significant Trend in Unit Root Test 
Phillips Perron tests were applied to age specific mortality rates for groups of ages across the countries in the study. The results are presented for the total population as well as male and females separately for the time period 1947-2004 in Tables 4, 5 and 6. These results do not reject the null hypothesis of unit roots and stochastic trends in the mortality data for most age groups with the excepton of the older age groups for many of the countries. There are also exceptions at the young ages. The mortality rates for most age groups are difference stationary and have stochastic trends, however some age groups in the younger and older age ranges have stationary levels.

\begin{tabular}{c|rrrrr}
\hline & Australia & England & Japan & Norway & USA \\
\hline 0 & 0.3683 & 0.01 & 0.3322 & 0.5111 & 0.911 \\
$1-4$ & 0.84 & 0.07918 & 0.265 & 0.09366 & 0.7684 \\
$5-9$ & 0.3601 & 0.08038 & 0.3388 & 0.01877 & 0.5006 \\
$10-14$ & 0.3656 & 0.08188 & 0.407 & 0.01 & 0.5124 \\
$15-19$ & 0.6379 & 0.07935 & 0.2577 & 0.01647 & 0.5159 \\
$20-24$ & 0.0823 & 0.3417 & 0.4527 & 0.0991 & 0.3376 \\
$25-29$ & 0.07799 & 0.5787 & 0.5797 & 0.2643 & 0.276 \\
$30-34$ & 0.3097 & 0.6166 & 0.5555 & 0.1737 & 0.3263 \\
$35-39$ & 0.4348 & 0.5174 & 0.5491 & 0.02134 & 0.4275 \\
$40-44$ & 0.7201 & 0.2305 & 0.5353 & 0.02136 & 0.6426 \\
$45-49$ & 0.8174 & 0.5781 & 0.572 & 0.2523 & 0.7928 \\
$50-54$ & 0.8685 & 0.8203 & 0.6028 & 0.7026 & 0.5869 \\
$55-59$ & 0.7903 & 0.937 & 0.6509 & 0.9597 & 0.4241 \\
$60-64$ & 0.866 & 0.9067 & 0.3533 & 0.99 & 0.6304 \\
$65-69$ & 0.8224 & 0.7357 & 0.3979 & 0.9459 & 0.5768 \\
$70-74$ & 0.6152 & 0.04969 & 0.01261 & 0.9076 & 0.2339 \\
$75-79$ & 0.1427 & 0.01 & 0.01 & 0.4163 & 0.5245 \\
$80-84$ & 0.01 & 0.01 & 0.01 & 0.4151 & 0.5244 \\
$85-89$ & 0.01 & 0.01 & 0.01 & 0.01 & 0.4517 \\
\hline
\end{tabular}

Table 4: Phillips-Perron Test P-values on Total Population data from 1947-2004

The analysis demonstrates that mortality rates for fixed ages across time, based on the historical population data for the countries in this study, are mostly difference stationary with stochastic trends. Time trends in mortality rates for fixed ages across time should be modeled as difference stationary where they have unit roots. Shocks across time are permanent for these ages and the volatility of mortality rates increases across time. Thus uncertainty about future mortality will increase with increased forecast horizons in contrast to trend stationary models that assume a long run stationary level of volatility. 


\begin{tabular}{c|rrrrr}
\hline & Australia & England & Japan & Norway & USA \\
\hline 0 & 0.1326 & 0.01 & 0.3486 & 0.6304 & 0.877 \\
$1-4$ & 0.5765 & 0.1035 & 0.288 & 0.07433 & 0.8269 \\
$5-9$ & 0.341 & 0.0821 & 0.3603 & 0.01 & 0.5457 \\
$10-14$ & 0.03578 & 0.2025 & 0.4586 & 0.01 & 0.5425 \\
$15-19$ & 0.01 & 0.379 & 0.3624 & 0.02191 & 0.2712 \\
$20-24$ & 0.02417 & 0.3826 & 0.5149 & 0.1088 & 0.1774 \\
$25-29$ & 0.06419 & 0.5619 & 0.6263 & 0.2963 & 0.2705 \\
$30-34$ & 0.137 & 0.6129 & 0.6267 & 0.2433 & 0.3935 \\
$35-39$ & 0.09029 & 0.4809 & 0.6658 & 0.02405 & 0.6009 \\
$40-44$ & 0.3017 & 0.08191 & 0.6646 & 0.0939 & 0.8282 \\
$45-49$ & 0.45 & 0.4498 & 0.7449 & 0.01 & 0.7071 \\
$50-54$ & 0.2743 & 0.6414 & 0.7754 & 0.06642 & 0.3745 \\
$55-59$ & 0.4196 & 0.7426 & 0.8399 & 0.1686 & 0.4122 \\
$60-64$ & 0.5061 & 0.6442 & 0.5281 & 0.0389 & 0.5427 \\
$65-69$ & 0.06818 & 0.01 & 0.686 & 0.01 & 0.7691 \\
$70-74$ & 0.04692 & 0.01 & 0.04052 & 0.01 & 0.745 \\
$75-79$ & 0.02268 & 0.01 & 0.01 & 0.01 & 0.8868 \\
$80-84$ & 0.01 & 0.01 & 0.01 & 0.0925 & 0.7888 \\
$85-89$ & 0.01 & 0.01 & 0.01 & 0.01 & 0.6491 \\
\hline
\end{tabular}

Table 5: Phillips-Perron Test P-values on Female Population data from 1947-2004

\begin{tabular}{c|rrrrr}
\hline & Australia & England & Japan & Norway & USA \\
\hline 0 & 0.3727 & 0.01 & 0.318 & 0.2529 & 0.9317 \\
$1-4$ & 0.7266 & 0.0503 & 0.2427 & 0.0812 & 0.7007 \\
$5-9$ & 0.04955 & 0.07487 & 0.3158 & 0.01 & 0.439 \\
$10-14$ & 0.01 & 0.02417 & 0.3406 & 0.01 & 0.4076 \\
$15-19$ & 0.6014 & 0.02812 & 0.1184 & 0.01 & 0.7237 \\
$20-24$ & 0.1032 & 0.1948 & 0.3769 & 0.03618 & 0.6611 \\
$25-29$ & 0.01457 & 0.5947 & 0.5261 & 0.09808 & 0.6728 \\
$30-34$ & 0.1085 & 0.6172 & 0.4862 & 0.03422 & 0.5582 \\
$35-39$ & 0.4073 & 0.5041 & 0.4342 & 0.01 & 0.4662 \\
$40-44$ & 0.678 & 0.2925 & 0.4101 & 0.01 & 0.5346 \\
$45-49$ & 0.854 & 0.5702 & 0.3739 & 0.9473 & 0.8249 \\
$50-54$ & 0.9175 & 0.7995 & 0.3743 & 0.9217 & 0.8142 \\
$55-59$ & 0.815 & 0.902 & 0.3544 & 0.9815 & 0.8295 \\
$60-64$ & 0.902 & 0.8852 & 0.08068 & 0.99 & 0.9281 \\
$65-69$ & 0.9149 & 0.9067 & 0.05159 & 0.99 & 0.9227 \\
$70-74$ & 0.8324 & 0.9504 & 0.01 & 0.99 & 0.9714 \\
$75-79$ & 0.7246 & 0.6394 & 0.01 & 0.99 & 0.9015 \\
$80-84$ & 0.07159 & 0.04272 & 0.01 & 0.6428 & 0.8649 \\
$85-89$ & 0.1651 & 0.01 & 0.01 & 0.01 & 0.383 \\
\hline
\end{tabular}

Table 6: Phillips-Perron Test P-values on Male Population data from 1947-2004 


\section{Principal Components Analysis}

A basic VAR time series model of age-specific death rates can be written as a system of equations for ages from 0 to $N$ including a drift $\mu(\cdot)$.

$$
\left[\begin{array}{c}
m(0, t) \\
m(1, t) \\
\vdots \\
m(N, t)
\end{array}\right]=\left[\begin{array}{c}
\mu_{0} \\
\mu_{1} \\
\vdots \\
\mu_{N}
\end{array}\right]+\tilde{\Phi}\left[\begin{array}{c}
m(0, t-1) \\
m(1, t-1) \\
\vdots \\
m(N, t-1)
\end{array}\right]+\left[\begin{array}{c}
\epsilon(0, t) \\
\epsilon(1, t) \\
\vdots \\
\epsilon(\hat{N}, t)
\end{array}\right] \quad \tilde{\Phi}=\left[\begin{array}{cccc}
\Pi_{0} & 0 & 0 & \ldots \\
0 & \Pi_{1} & 0 & \ldots \\
\vdots & \vdots & \ddots & \vdots \\
0 & 0 & \ldots & \Pi_{N}
\end{array}\right]
$$

where $\Pi_{i}$ is the coefficient of the lagged mortality rate time series for age $i$.

The errors have covariance matrix:

$$
\operatorname{cov}\left[\epsilon(t), \epsilon(t)^{T}\right]=\left[\begin{array}{cccc}
\sigma_{1,1} & \sigma_{1,2} & \ldots & \sigma_{1, N} \\
\sigma_{2,1} & \sigma_{2,2} & \cdots & \sigma_{2, N} \\
\vdots & \vdots & \ddots & \vdots \\
\sigma_{N, 1} & \sigma_{N, 2} & \cdots & \sigma_{N, N}
\end{array}\right]
$$

Principal Components Analysis (PCA) can then be used to identify factors driving the volatility after removing the trend through the drift term. The number of factors is determined by the eigenvalues of the variance-covariance matrix of the errors. The effects of the factors across age is given by the eigenvectors of the variance-covariance matrix.

Dimension reduction is necessary for efficient handling of large data sets such as mortality rates for many time periods. Principal components analysis or singular value decomposition (Martinez and Martinez 2005) are a means of doing this dimension reduction leading to a more parsimonious model for practical applications.

Singular value decomposition (SVD) gives the minimum number of dimensions required to represent an $m \times n$ data matrix, say, $\mathbf{A}$ that can be decomposed as:

$$
\mathbf{A}=U \Sigma V^{T}
$$

such that

$U$ and $V^{T}$ are orthogonal matrices

$\Sigma$ is a diagonal matrix with the singular values of $\mathbf{A}$ as the diagonal elements.

If some entries $\left\{\sigma_{i, i}\right\}$ on the diagonal of $\Sigma$ are zero, then for some $d$, 
$\sigma_{1} \geq \sigma_{2} \geq \cdots \geq \sigma_{d} \geq \sigma_{d+1}=\ldots=\sigma_{m}=0$. Then $\Sigma V^{T}$ is a $d x n$ matrix with dimension $d<n$.

Hotelling (1933) suggests PCA for quantifying factors that affect the data when the factors are not explicitly given. PCA determines the eigenvectors corresponding to the largest eigenvalues of the covariance matrix. One way to determine the number of principal components to use is by looking at the percentage of variance explained or the characteristics of the singular values. The first step in PCA is to center the data around its mean, then compute the covariance matrix of the data. The total variance of $m \times n$ matrix $\mathbf{A}$ with element $a_{i, j}$ is:

$$
E\left[\mathbf{A}-\underline{\mu_{\mathbf{A}}}\right]^{2}=\sum_{i=1}^{m} \operatorname{Var}\left[a_{i}\right]=\sum_{i=1}^{m} \sigma_{i i}=\operatorname{tr} \boldsymbol{\Sigma}_{\rho} ; \quad \underline{\mu_{\mathbf{A}}}=E[A]
$$

$\boldsymbol{\Sigma}_{\rho} \geq \mathbf{0}$, the covariance matrix, can be written as $\boldsymbol{\Sigma}_{\rho}=\mathbf{H} \mathbf{D} \mathbf{H}^{\mathbf{T}}$ where $\mathbf{D}=\operatorname{diag}\left(\lambda_{1} \geq \lambda_{2} \geq \ldots \geq \lambda_{m}\right)$ for the ordered eigenvalues $\lambda_{i}$ of $\boldsymbol{\Sigma}_{\rho}$ and $\mathbf{H}=$ $\left(\mathbf{h}_{1}, \mathbf{h}_{2}, \ldots \mathbf{h}_{\mathbf{m}}\right)$ with $h_{i}$ as orthogonal matrices. The principal components are computed as the eigenvectors of the variance-covariance matrix $\boldsymbol{\Sigma}_{\rho}$ and the associated variance is described by the corresponding eigenvalues.

Figure 8 gives the PC's for the mortality rate levels of Female, Male and Total age specific death rates for Australia. In order to explain $90 \%$ of the variance in the data, the number of principal components required are 4, 5 and 4 for females, males and the total population respectively. Each principal component also explains a different percentage of the variance. For example, the first component explains $72.8 \%, 50.3 \%$ and $69.1 \%$ of the variation of each of the three groups respectively.
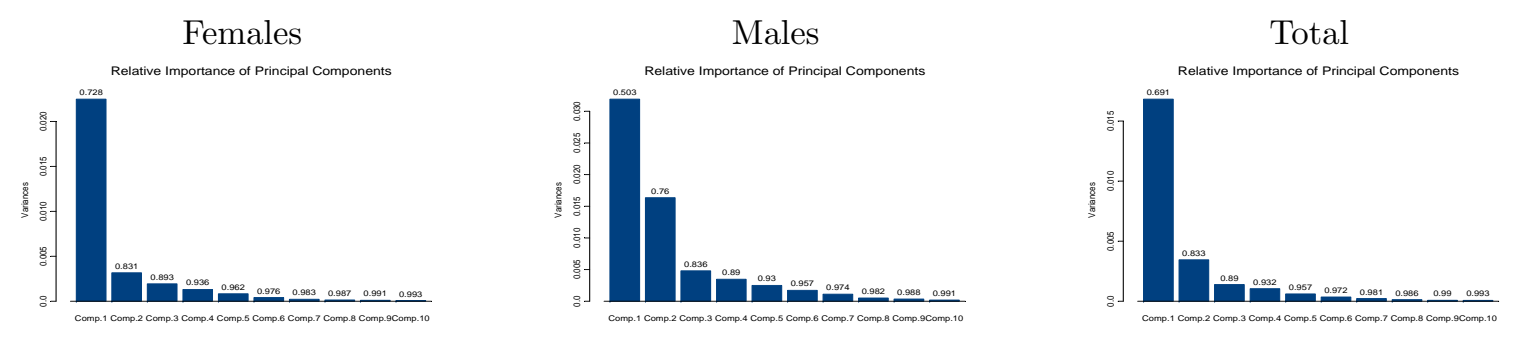

Figure 8: Principal Components for Australia and Mortality rate levels

PCA was carried out for the time trends, based on errors for horizontal differences of the mortality rates, from the simple VAR model for the age based mortality data. This determines the number of factors that affect 
mortality over time for the various ages. PCA was performed for each country on the time differences of the levels of the mortality data assuming a first order stochastic trend. A summary of the results is in Table 7 giving the number of PC's that explain $98 \%$ of the variation.

Models based on deterministic trends for the level of mortality rates should include a larger number of factors driving mortality changes than the one common factor assumed in the Lee-Carter model. There is also a similar number of factors across the countries suggesting the possibility of common factors across countries. This similar number of factors holds for both time trends (horizontal differences) and cohort trends (diagonal differences). This is not surprising since the cohort trends include the time trends along with an age effect. The number of factors is much higher in the differences of the levels than in the levels themselves.

\begin{tabular}{l|lcc}
\hline Country & Difference & Number of Factors & Percentage Variation \\
\hline Australia & Diagonal & 8 & 98.7 \\
& Horizontal & 8 & 98.6 \\
England & Diagonal & 7 & 98.6 \\
& Horizontal & 7 & 98.9 \\
\multirow{5}{*}{ Norway } & Diagonal & 6 & 98.8 \\
& Horizontal & 5 & 98.1 \\
\cline { 2 - 4 } & Diagonal & 9 & 98.4 \\
& Horizontal & 8 & 98.1 \\
& Diagonal & 10 & 97.4 \\
& Horizontal & 10 & 97.7 \\
\hline
\end{tabular}

Table 7: PCA Factors using for differences in rates for countries in study

Figure 9 gives a plot of the principal components for different countries. Each principal component affects mortality at different ages in a different way. The common feature for the different countries is that for the lower ages the effects are fairly constant but at different intensities. At the higher ages (above age 75 ) there is a lot more variability in the way each principal component affects a specific age's mortality change. The first principal component has a similar general effect in all five countries being initially fairly constant and then decreasing as age increases. The second principal component for Japan and the third principal component for USA both increase as age increases. This may be the same principal component but its order differs for each country. For some countries, such as Japan, the PC's are more variable, while for the other countries they appear relatively constant between age 75 and age 85 . 

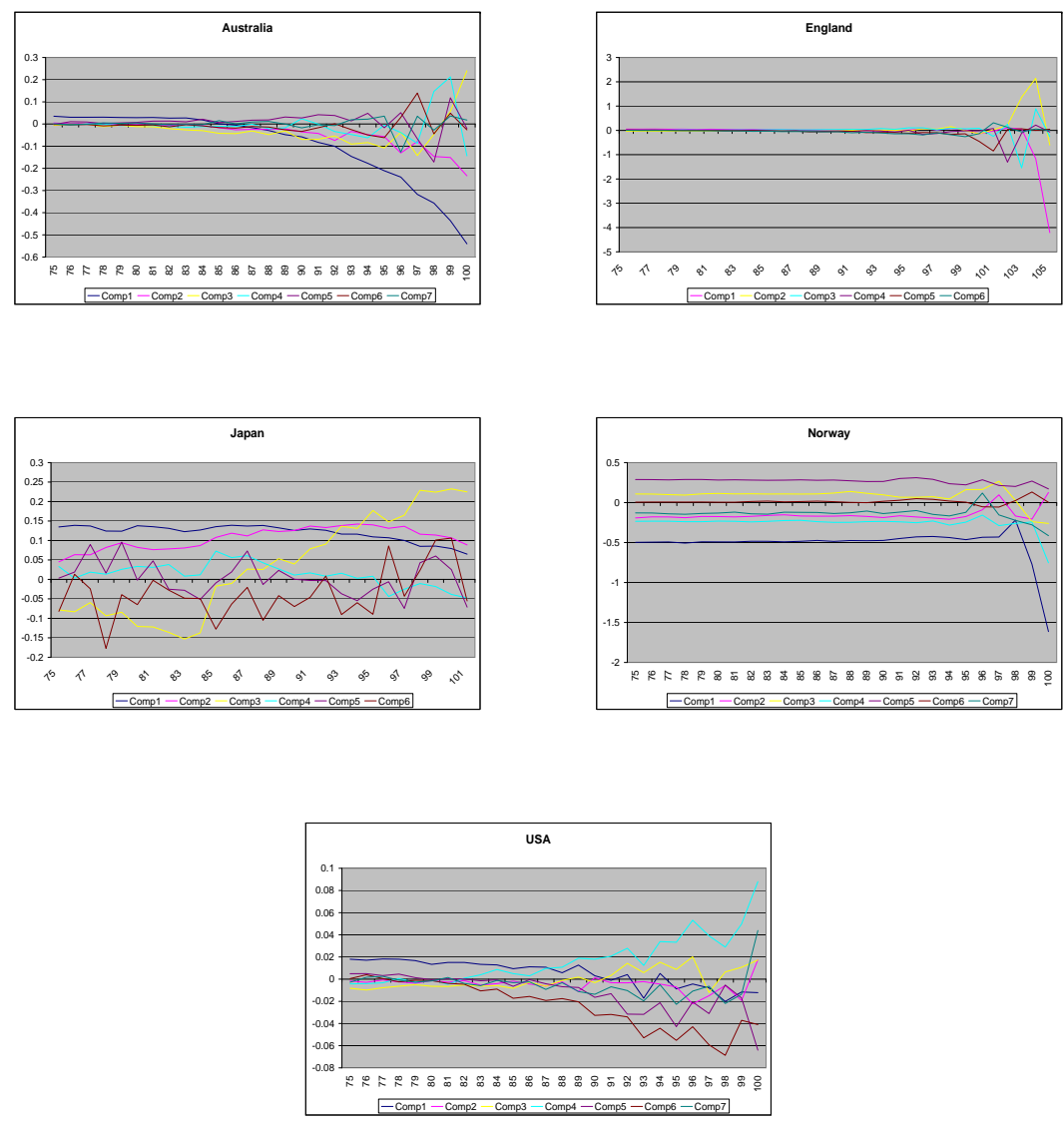

Figure 9: Multiple PCA Factors for Mortality Differences

\section{Cointegration}

Variables are said to be cointegrated if they have a common stochastic trend (Lütkepohl and Krätzig 2004). Cointegrated time series are affected by common factors and their permanent trends lead the time series to eventually attain an equilibrium (steady state). This is useful in modelling mortality rates. There exist shocks that drive the mortality system. These shocks are generally unobservable. In multivariate cointegration analysis all variables are assumed to be stochastic and a random shock to one variable is transmitted to all the other variables in the system until the system moves to a new equilibrium position. Treating mortality at each age as a non-stationary variable, cointegration allows the determination of the ages that have experienced similar persistence of random shocks. The unit root tests show that the trends in mortality improvement should be modeled as difference 
stationary. They have stochastic trends through time and the major shocks to mortality rates accumulate in the series. These non-stationary time series require a transformation such as differencing to obtain stationarity.

The underlying long-run information of a non-stationary time series is removed if the data is detrended or differenced. Cointegration analysis can be used to model the long-run relationship and retain statistical information. We can therefore use cointegration analysis to study if there exist long-run relationships between age specific death rates and for different countries.

Non-stationary time series variables possess the property of cointegration when a linear combination of the time series is stationary (Engle 1987, Juselius 2006, Pfaff 2008) and these variables should not wander arbitrarily far from each other (diverge) in the long run.

A linear combination of two $I(1)$ variables is usually $I(1)$. Generally, a combination of variables with different orders of integration has an order of integration equal to the largest order of integration. This implies that a linear combination of non-stationary mortality time-series should also be non-stationary with an order of integration equal to the largest order of integration of the mortality time-series.

In the simplest case, two $I(1)$ time series, $\left\{Y_{t}\right\}$ and $\left\{Z_{t}\right\}$, are said to be cointegrated if for a linear combination of the two series there exists a cointegrating parameter, $\beta$, such that the difference, $\varepsilon_{t}=Z_{t}-\beta Y_{t}$, is stationary. $Z_{t}=\beta Y_{t}$ is defined as the long run or equilibrium relationship between $\left\{Y_{t}\right\}$ and $\left\{Z_{t}\right\}$.

Some studies have analyzed cointegration in mortality but with emphasis on how cointegration affects Lee-Carter (Chan 2008) and the cointegration of the parameters in the Lee-Carter model (Darkiewicz and Hoedemakers 2004; Lazar 2004). Darkiewicz and Hoedemakers (2004) suggest that cointegration analysis can be used as a diagnostic check of the validity of the Lee-Carter model. They do cointegration analysis of England and Wales log-mortality rates. Lazar (2004) finds that for Romanian mortality rates at high ages $(63+)$ and given Lee-Carter's $\ln m(x, t)$ and $k(t)$, if the ages are pairwise cointegrated then the Lee-Carter model is the cointegration relation. The Lee-Carter model can be written as a cointegration relation when $x$ is fixed:

$$
z_{t}=a+b y_{t}+\varepsilon_{t}
$$


as compared with

$$
\ln m(x, t)=\alpha(x)+\beta(x) k(t)+\epsilon(x, t)
$$

$z_{t}$ (or $\left.\ln m(x, t)\right)$ and $y_{t}($ or $k(t))$ evolve together in time with a long term equilibrium disturbed by random shocks with short-term effects.

Following Pfaff (2008), once it has been established that there exists a unit root, it is necessary to specify an error correction model (ECM) where the changes in the value of a time series variable are explained in terms of its own past values, lagged changes in other time series variables in the system and residuals. The $\operatorname{VAR}(\mathrm{p})$ model explains endogenous variables using their own history. In order to analyse the cointegration structure vector error correction models (VECM) are used because cointegration relations do not appear explicitly in $\operatorname{VAR}(\mathrm{p})$ models for time series with stochastic trends.

$\mathrm{A} \operatorname{VAR}(\mathrm{p})$ for $p$ lags is written as:

$$
m_{t}=A_{0}+A_{1} m_{t-1}+A_{2} m_{t-2}+\cdots+A_{p} m_{t-p}+e_{t}
$$

where $\mathbf{m}_{t}=\left(m_{1 t}, \ldots, m_{k t}, \ldots, m_{K t}\right)$ for $k=1, \ldots, K$ time series. The key assumptions in the $\operatorname{VAR}(\mathrm{p})$ model are that there is no serial correlation and no heteroscedasticity in the residuals and that the residuals are normally distributed. A VAR(p) model is stable if it generates stationary time series over a long time period (Pfaff (2008) and this stability is indicated by eigenvalues of $A_{0}$ that are less that one. Choice of $\operatorname{VAR}(\mathrm{p})$ is largely influenced by the lag order, $p$. The optimal lag length is determined by use of information criteria such as Akaike's AIC and Schwarz's SIC or by use of Akaike's final prediction error (FPE) whereby the most accurate model has the smallest FPE.

Several VAR(p) models are usually estimated then analysed to check that the models assumptions hold based on diagnostic tests. To test for serial correlation of the residuals a Portmanteau test is performed (Harvey 1991), to test for heteroscedasticty ARCH tests are performed while to test for normality of the residuals normality tests such as the Jarque-Bera test are performed.

Once the appropriate $\operatorname{VAR}(\mathrm{p})$ has been estimated then it is converted to a vector error correction model. The long-run specification of the VECM is:

$$
\Delta \mathbf{m}_{t}=\Gamma_{1} \Delta \mathbf{m}_{t-1}+\cdots+\Gamma_{p-1} \Delta \mathbf{m}_{t-p+1}+\Pi \mathbf{m}_{t-p}+A_{0}+e_{t}
$$


where

$\Gamma_{i}=-\left(I-A_{1}-\cdots-A_{i}\right), \quad i=1, \ldots, p-1 \quad \Pi=-\left(I-A_{1}-\cdots-A_{p}\right)$

Alternatively, the transitory specification of the VECM is:

$$
\Delta \mathbf{m}_{t}=\Gamma_{1} \Delta \mathbf{m}_{t-1}+\cdots+\Gamma_{p-1} \Delta \mathbf{m}_{t-p+1}+\Pi \mathbf{m}_{t-1}+A_{0}+e_{t}
$$

where

$$
\Gamma_{i}=-\left(A_{i+1}+\cdots+A_{p}\right), \quad i=1, \ldots, p-1 \quad \Pi=-\left(I-A_{1}-\cdots-A_{p}\right)
$$

In the long-run form of the VECM the levels of the components of $\mathbf{m}_{t}$ enter the model lagged at $t-p$ while in the transitory specification they enter the model lagged by 1 .

Vector Error Correction Models for a VAR(p) can be described in either a long-run form or a transitory (short-run) form. Each includes lagged differences of $\mathbf{m}_{t}$ and an error correction term that must be stationary for the VECM to be balanced (stationary on both the right hand side and the left hand side of the equation). For $\mathbf{m}_{t}$ whose components are at most $I(1)$ time series, the left hand side of the VECM is stationary due to first differences and the right hand side is stationary due to the stationary error correction terms.

The long run equilibrium, $\Pi$, is the same in both specifications of the VECM hence it does not matter which form of VECM is used in order to analyse $\Pi$ (Juselius 2006, Pfaff 2008, Lütkepohl and Krätzig 2004). The stationarity of the error correction terms depends on characteristics of the matrix $\Pi$. The rank of the matrix $r k(\Pi)=r$ gives the maximum number of linearly independent rows/colomns of the matrix, $\Pi$. This rank, $r$, (the cointegration rank of the system $\mathbf{m}_{t}$ ) is the number of cointegration relationships present in the system (Lütkepohl and Krätzig 2004). In cointegration studies there are 3 cases to consider:

Case 1. $r=K$, all linear combinations are stationary and a VAR model in levels should be used

Case 2. $r=0$, there are no linear combinations that are stationary except for any trivial solution and a VAR model in differences should be used

Case 3. $0<r<K$, so that there exist two matrices $\alpha$ and $\beta$ such that $\Pi=\alpha \beta^{\prime}$. 
$\Pi$ is of reduced rank and cointegrating relations must be incorporated in the VAR through a VECM.

Since $\Delta m_{t}$ is stationary the only term that may not be stationary is $\Pi m_{t-p}$ (Juselius 2006). It is necessary to select $\Pi$ such that $\Pi m_{t-p}=\alpha \beta^{\prime} m_{t-p}$ is stationary or alternatively $\beta^{\prime} m_{t-p}$ is stationary. Since $\beta$ may not be unique, one element of $\beta$ is usually normalised to one. The parameters $\alpha$ give the sensitivity to the long-run equilibrium and is referred to as the loading matrix. An initial step in testing for cointegration involves testing the alternative hypothesis $H_{1}: \Pi=\alpha \beta^{\prime}$ by computing trace and eigenvalue statistics. These statistics are discussed in Juselius (2006) and Lütkepohl and Krätzig (2004).

For a $\operatorname{VAR}(2)$ model the VECM would be:

$$
\Delta \mathbf{m}_{t}=\Gamma_{1} \Delta \mathbf{m}_{t-1}+\Pi \mathbf{m}_{t-2}+A_{0}+e_{t}
$$

where

$$
\Gamma_{1}=-\left(I-A_{1}\right), \quad \Pi=-\left(I-A_{1}-A_{2}\right)=\alpha \beta^{\prime}
$$

The cointegrating vector, $\beta$ is the long-run equilibrium of the error correction model. The $\alpha$ can be considered as a measure of how much each cointegration equation (stationary linear combination) impacts changes in each of the variables.

\section{Cross-Country Mortality Rate Cointegration}

Population mortality rates across countries are expected to contain common stochastic trends and to be cointegrated based on the previous analysis. The mortality rates for males and females differ and are analysed separately based on the standardized age specific mortality rates for Australia, England, Japan, Norway and USA from 1947-2004.

This analysis is carried out for the standardized country mortality rates to estimate long run equilibrium common stochastic trends by estimating a VAR model, and if required, a VECM model that incorporates those long run stochastic trends. This allows data to be combined across countries leading to more efficient estimates of future mortality rates and providing information about the relationship between the different countries mortality improvement and longevity risk.

For mortality rates that are cointegrated econometric models can be used 
to estimate the long run relationships between the countries and how changes in country mortality rates respond to departures from the long run equilibrium between the mortality rates. The technique used is Johansen's Methodology (Juselius 2006). After determining the number of lags, $p$, a $\operatorname{VAR}(p)$ model is estimated. The number of cointegrating relations in the estimated model is then determined. This is used to estimate the VECM and the cointegrating coefficients. The analysis was implemented in R-statistical using the methodology outlined in Pfaff (2008).

Denoting $\mathrm{A}=$ Australia, $\mathrm{E}=$ England and Wales, $\mathrm{J}=$ Japan, $\mathrm{N}=$ Norway and $\mathrm{U}=\mathrm{USA}$, then a $\operatorname{VAR}(1)$ model for this system would be specified as:

$$
\mathbf{m}_{t}=A_{0}+A_{1} \mathbf{m}_{t-1}+u_{t}
$$

where

$$
\begin{gathered}
\mathbf{m}_{t}=\left(\begin{array}{c}
m_{A, t} \\
m_{E, t} \\
m_{J, t} \\
m_{N, t} \\
m_{U, t}
\end{array}\right) ; \quad \Delta \mathbf{m}_{t}=A_{0}+\Pi \mathbf{m}_{t-1}+u_{t} \\
\Pi=\alpha \beta^{\prime}=-\left(I-A_{1}\right) \\
\beta=\left(\beta_{A}, \beta_{E}, \beta_{J}, \beta_{N}, \beta_{U}\right)
\end{gathered}
$$

The matrix $P i$ gives the long-run equilibrium parameters. Cointegration implies that $\Pi$ is of reduced rank with $r k(\Pi)=r$ where $r$ is the number of cointegration relationships that exist between the variables referred to as the cointegration rank. The $\alpha$ parameters are the loading matrix while $\beta$ contains the coefficients of the long run relationships such that $\beta^{\prime} \mathbf{m}_{t-1}$ is the cointegrating relations.

The unit root tests indicated there may be cointegration of the mortality rates for the five countries. A VAR model is estimated then diagnostic tests are performed to assess the assumptions of the VAR model. There should be no serial correlation and no heteroscedasticity in the residuals and the residuals should be normally distributed.

The VAR model was initially applied to the levels of the mortality rates. The optimal lag length, $p$, for an unrestricted VAR model to analyse the cointegration was determined. A range of information criteria including the $\mathrm{AIC}$ and the final prediction error were used but it is also important to have a parsimonious model with as few lags as possible. For the time period from 1963 to 2004 a VAR model was estimated including a constant and a trend as the deterministic regressors. The estimates for $\operatorname{VAR}(1)$ and $\operatorname{VAR}(2)$ models 
for the levels of the Australian standardized mortality rates are given in Figure 10 and Figure 11. These show that a VAR(1) model for the Australian mortality rates is appropriate and that the $\mathrm{ACF}$ and $\mathrm{PACF}$ demonstrate the model captures autocorrelation. However, based on the test statistics, the errors were serially correlated which makes inference for parameters and goodness of fit unreliable based on the assumption of no serial correlation.

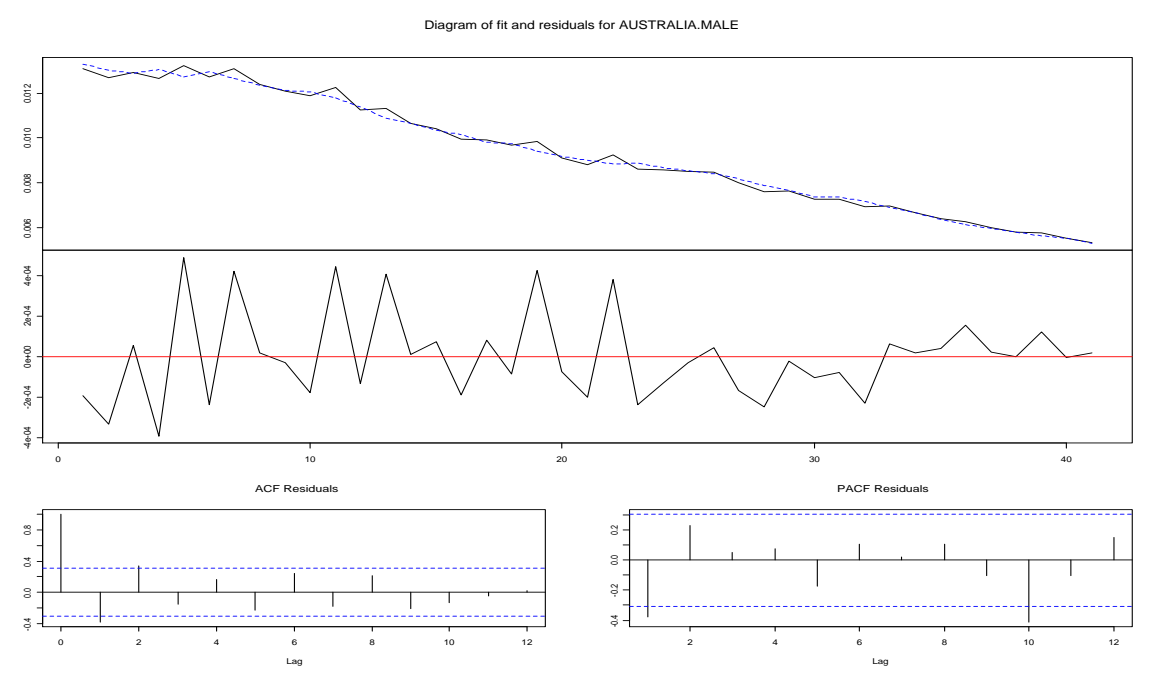

Figure 10: Estimated Australian Male Mortality rates using VAR(1)

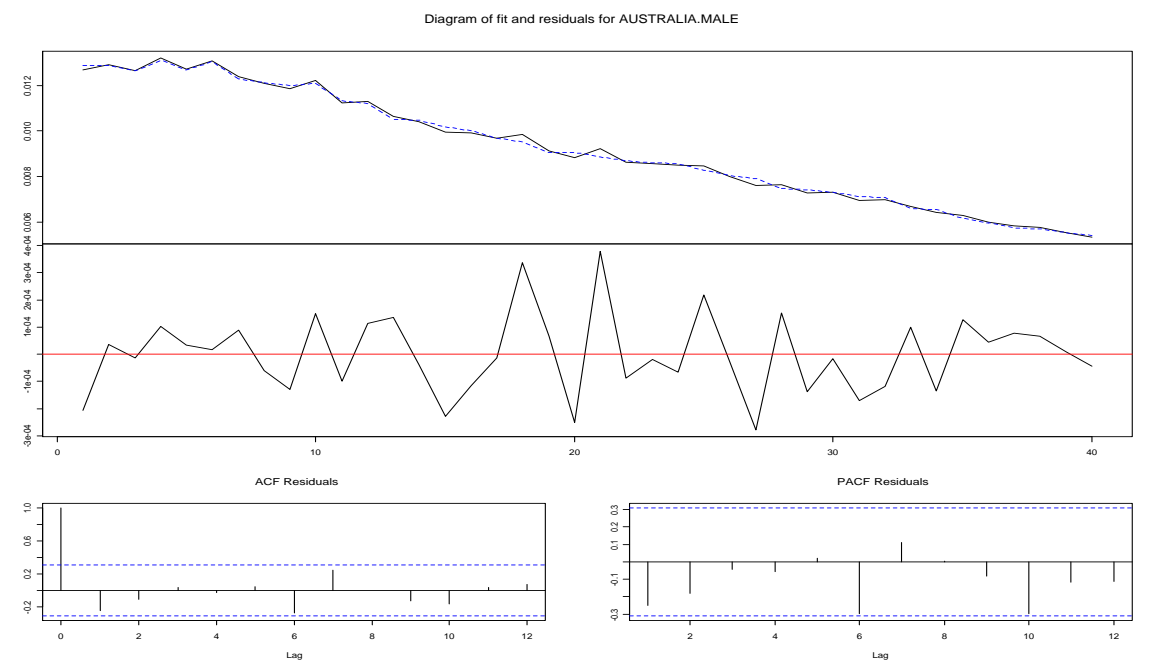

Figure 11: Estimated Australian Male Mortality rates using VAR(2)

Similar figures can be produced for each of the countries to confirm the model fit. However the serial correlation of the errors suggests a transform of the 
data. A similar analysis using a log transform of the standardized rates for each country also showed that the non-seriality assumption for the residuals holds. The Box-Cox transform is often used in econometrics and a special case is the log transform. Models were also fitted for lags $p=1$ and $p=2$. Diagnostic tests were conducted on the estimated models to determine which transformation and which number of lags, $p$, would yield the best $\operatorname{VAR}(\mathrm{p})$.

A Portmanteau Test was performed to test for autocorrelation of the disturbances. The null hypothesis is that the coefficients of the lags of disturbances are zero up to a given lag, $h,\left(H_{0}\right.$ : the disturbances are not autocorrelated). The test statistic of the Portmanteau Test, $Q$, is computed and the p-value reported in Table 8. If the null hypothesis is rejected then at least one value of the coefficients of the disturbances is statistically different from zero at the specified significance level. These results were based on a maximum lag of 7 . These tests illustrate that the logarithm of the standardized rates along with a $\operatorname{VAR}(1)$ model capture the auto-correlation in the series. This is not the case for the levels of the standardized rates. In the $\operatorname{VAR}(2)$ statistics report that the model performs worse in terms of serial correlation.

A Jarque-Bera Test is performed on the residuals of the estimated $\operatorname{VAR}(\mathrm{p})$ models to determine which model has residuals that are close to normality. Deviation from normality increases the Jarque-Bera Test statistic.

The analysis demonstrates that a $\operatorname{VAR}(1)$ model is appropriate for both males and females based on the logarithms of the standardized rates. For this model the normality assumption for the residuals is not rejected and the model captures all significant serial correlations. Plots are shown in figures 12 and 13 for Males and Females respectively.

The $\operatorname{VAR}(1)$ model estimated has $\Pi=-\left(I-A_{1}\right)$ with determinant different from zero so that $r=k=5$ and there are no cointegration relations. From Triacca (2002), if the elements of $m_{t}$ are not cointegrated then $\Pi m_{t-1}$ is $I(1)$. This means that $u_{t}$ are $I(1)$. From the unit root tests it was found that $\Delta \ln m_{t}$ are stationary so that $\Pi$ is the null matrix and hence, $\Delta \ln m_{t}=u_{t}$. It is sufficient to model the differences of $\ln m_{t}$ for these countries in a VAR model. There are no common stochastic country trends based on these results.

This analysis has demonstrated how the standardized mortality rates across countries have stochastic trends based on the historical data. These stochastic trends are not common to all the countries in this analysis. Model- 


\begin{tabular}{|c|c|c|c|}
\hline & Males & Females \\
\hline & & \multicolumn{2}{|c|}{ VAR $(1)$} \\
\hline \multirow[t]{2}{*}{ Log-Likelihood } & Level & 1521.399 & 1604.207 \\
\hline & Log-level & 571.404 & 555.344 \\
\hline \multirow{2}{*}{ Portmanteau Test } & Level & 0.006157 & 0.0079 \\
\hline & Log-level & 0.1194 & 0.2256 \\
\hline \multirow{2}{*}{ Jarque-Bera Test } & Level & 0.3508 & 0.7489 \\
\hline & Log-level & 0.5329 & 0.9033 \\
\hline & & \multicolumn{2}{|c|}{$\operatorname{VAR}(2)$} \\
\hline \multirow[t]{2}{*}{ Log-Likelihood } & Level & 1527.921 & 1609.767 \\
\hline & Log-level & 586.789 & 567.241 \\
\hline \multirow[t]{2}{*}{ Portmanteau Test } & Level & 0.0001125 & 0.0019 \\
\hline & Log-level & 0.0115 & 0.0410 \\
\hline \multirow[t]{2}{*}{ Jarque-Bera Test } & Level & 0.388 & 0.6947 \\
\hline & Log-level & 0.2797 & 0.8976 \\
\hline
\end{tabular}

Table 8: Diagnostic results for VAR(p) for cross country model

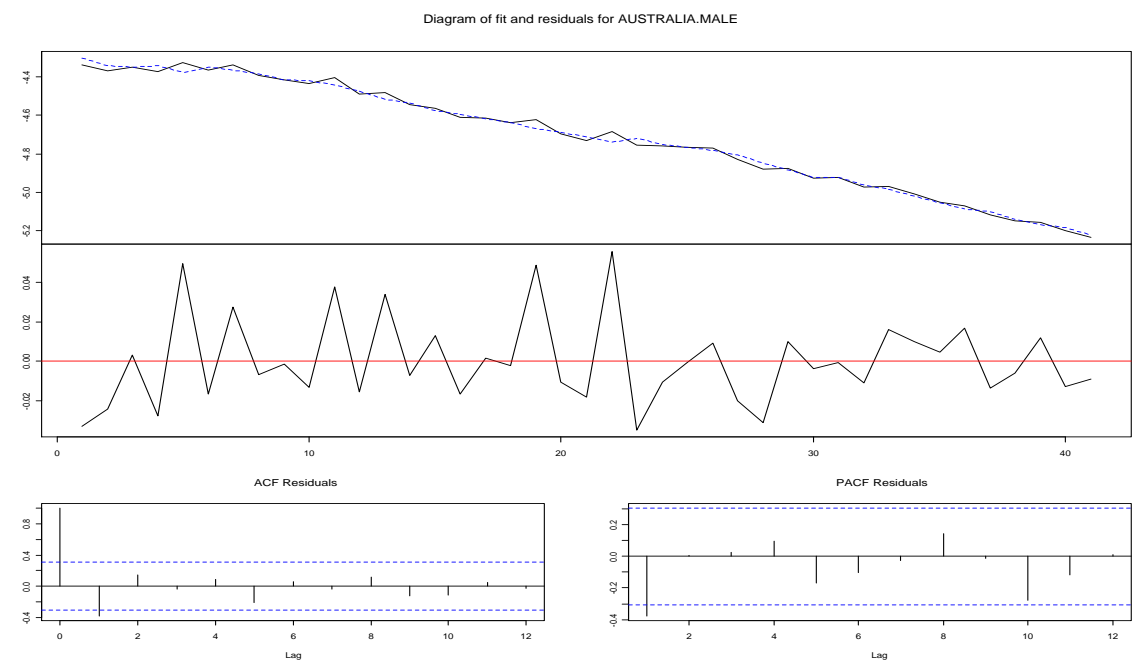

Figure 12: Estimated Australian Male Log-Mortality rates using VAR(1)

ing the differences of the standardized mortality rates is sufficient to capture trends for each country at the aggregate level. This has implications for international diversification of longevity risk since there are no common long run relationships between countries mortality improvement and potential for risk diversification across countries. 
Diagram of fit and residuals for AUSTRALIA.FEMALE

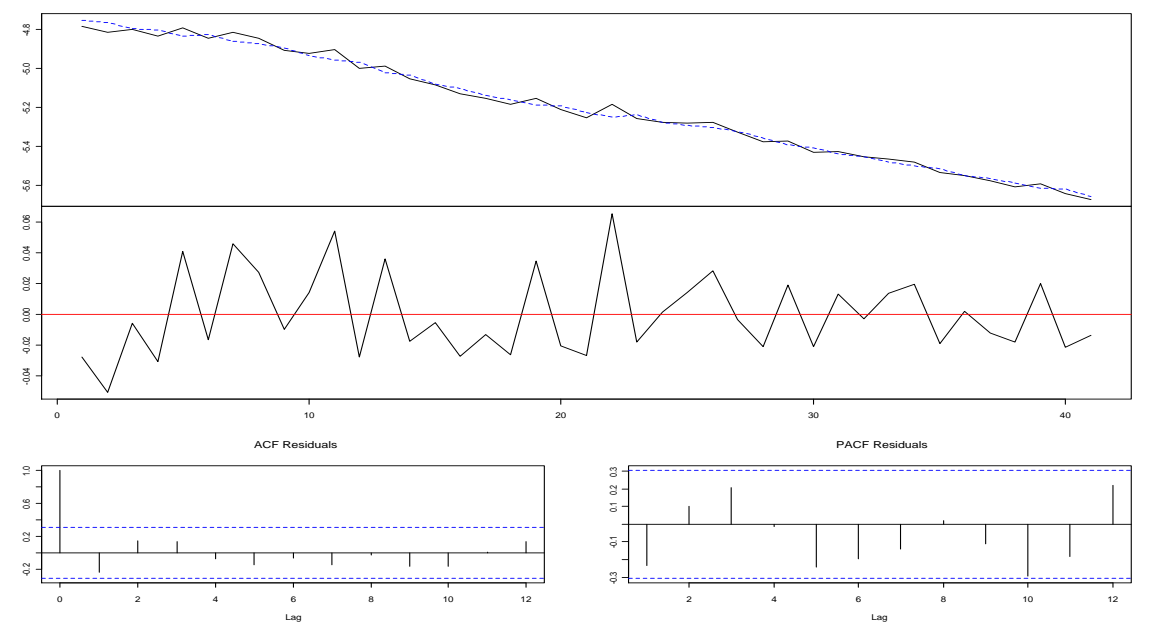

Figure 13: Estimated Australian Female Log-Mortality rates using VAR(1)

\section{Australian Mortality Rate Trends and Volatilities}

In this section the application of VECM and VAR models to Australian male and female age specific mortality rates is developed. Earlier analysis indicated the need for up to 8 random factors and that some ages are potentially cointegrated. There have been no studies applying multivariate econometric modeling techniques to mortality data allowing for cointegration and nonstationarity for a range of ages. Early application of time series to mortality data appears in McNown and Rogers (1989). In order to reduce the number of random factors driving mortality changes over time a parameterized mortality model is cross sectionally estimated at a series of points in time and the evolution of the parameters is modeled as a VAR/VECM system. This not only reduces the dimension of the random variability but allows for smoothing across ages and improved forecasting performance of the model.

Following McNown and Rogers (1989) a modification of the eight parameter model proposed by Heligman and Pollard (1980) is used to model the probability of death of an individual aged $x$ in the next year, $q_{x}$ as:

$$
q_{x}=A^{(x+B)^{C}}+D \exp \left[-E\left(\log \left\{\frac{x}{F}\right\}\right)^{2}\right]+\frac{G H^{x}}{1+G H^{x}}
$$

The resulting curve is continuous over the entire age range.

Each of the three terms in Equation 28 represents a distinct component of mortality and each of the parameters has a demographic interpretation. 
$A^{(x+B)^{C}}$ is a rapidly declining exponential that reflects the fall in mortality during the early childhood years. In particular, $A$ is a measure of mortality at age $1 ; B$ is an age displacement factor that accounts for infant mortality; and $C$ is a measure of the rate of mortality decline in childhood.

$D \exp \left[-E\left(\log \left\{\frac{x}{F}\right\}\right)^{2}\right]$ reflects young adult mortality and for males mainly reflects the accident mortality whereas it reflects also maternal mortality for females. The accident hump usually lies between age 10 and 40. F measures the location of the accident hump, $E$ measures its spread and $D$ measures its severity.

$\frac{G H^{x}}{1+G H^{x}}$ is the Gompertz exponential mortality for older ages. It captures the incease in mortality due to the natural aging process of the body, referred to as senescence. $G$ measures the base level of older age mortality and $H$ is the rate of increase in $G$ with age.

The Heligman-Pollard model was fitted to the central mortality rates derived by transforming $m_{x}$ to $q_{x}$ using:

$$
q_{x}=\frac{2 m_{x}}{2+m_{x}}
$$

The mortality rates $q_{x}$ for $x=0,1, \ldots, 90$ were used to fit the HeligmanPollard model for the years 1946-2004 for Australia for both males and females. The parameters were estimated by minimizing the weighted sum of squared errors between observed, $q_{x}$ and the fitted, $\hat{q}_{x}$ :

$$
S^{2}=\sum_{x=0}^{90} \frac{1}{q_{x}^{2}}\left(\hat{q}_{x}-q_{x}\right)^{2}
$$

Hartmann (1987) discusses estimation issues for the Heligman-Pollard model. In the following figures, the dotted line represents the observations while the continuous (red) line represents the fitted Heligman Pollard model for various years fitted to the male Australian mortality data. The figures on the left are $q_{x}$ and those on the right are $\log \left(q_{x}\right)$ which more clearly shows the accident hump.

The model fits the data well and provides a consistent basis for smoothing across age. The fitted parameters are shown in the following graphs. They show how the trends in the different mortality experiences for different ages have varied through time and also highlight the variability in the trends.

Declining $A$ shows how mortality at age one has been declining through 

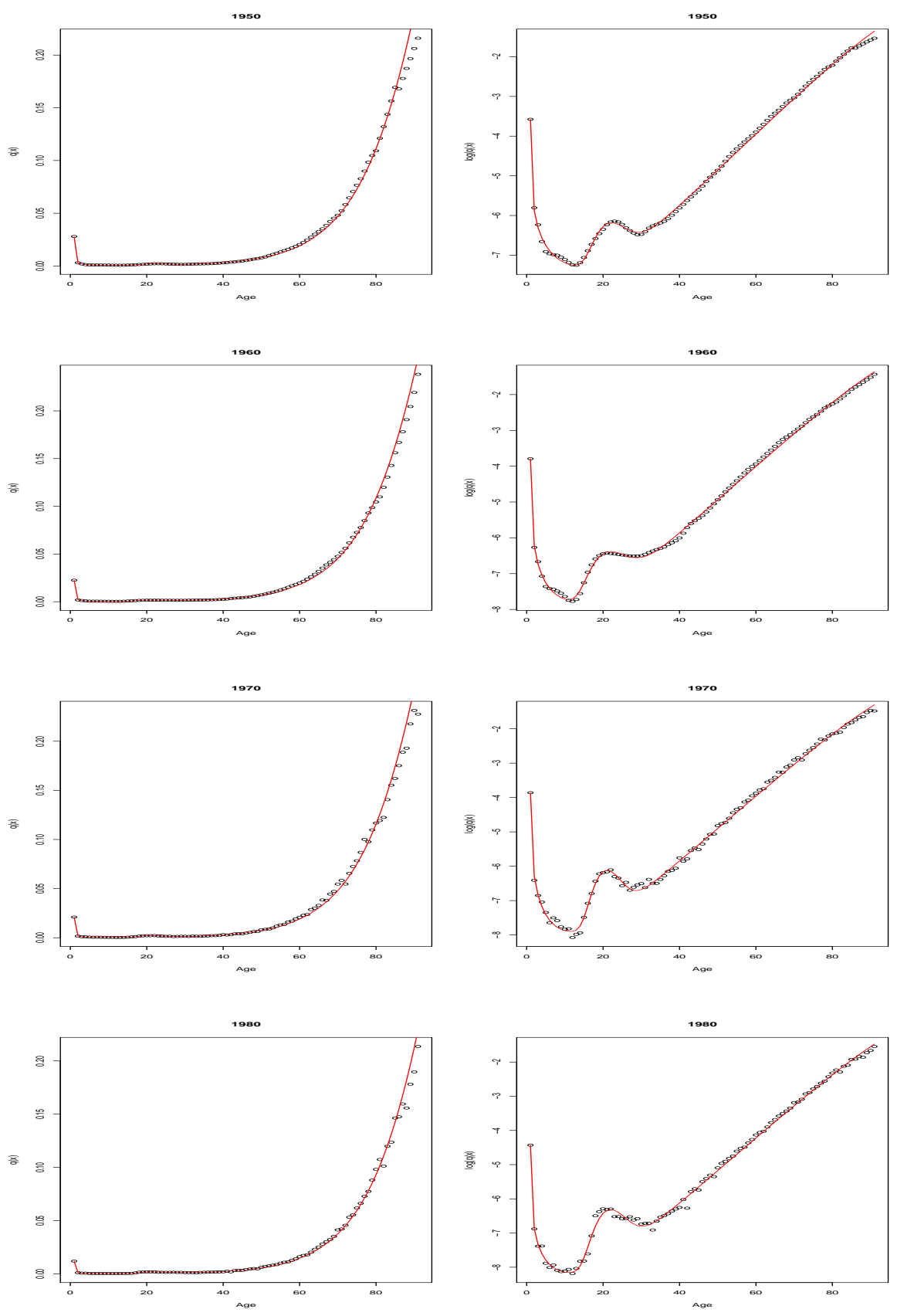

the period. The rate of decline was quite rapid from the mid 1950s to the early 1960s and has since slowed down. Changes in $B$ show how the mortality trends in the first years of age have been variable. Mortality in childhood is reflected in $C$ and shows a downward trend between the mid 1950s and the mid 1980s with considerable volatility. The intensity of young adult mortality, $D$, for males was low immediately post world war II, rose sharply in the early 1950s, dropped again in the mid 1960s then rose sharply during 

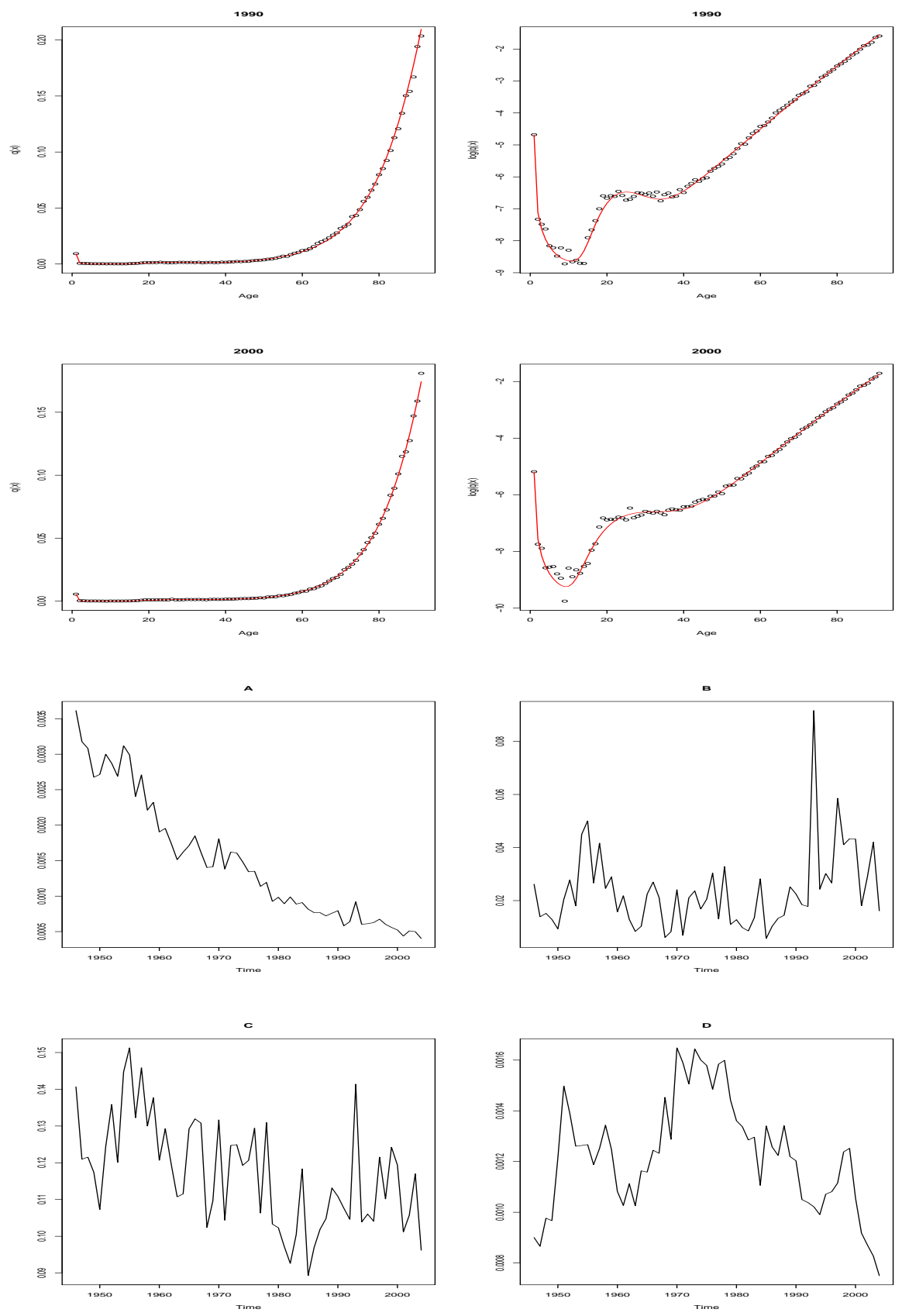

the 1970 s. $E$ is inverse to the spread of the accident hump. As $E$ gets smaller, the accident hump is more spread out. Since the mid 1970s the accident hump spread has been increasing. $F$ gives the modal age or location of the accident hump and this has been increasing. $G$ captures the base level of senescent (old age) mortality and has has a steady downward trend. $H$ reflects the rate of increase in mortality due to senescence $(G)$ as age increases. This has been increasing so that although the overall level of old age mortality has 

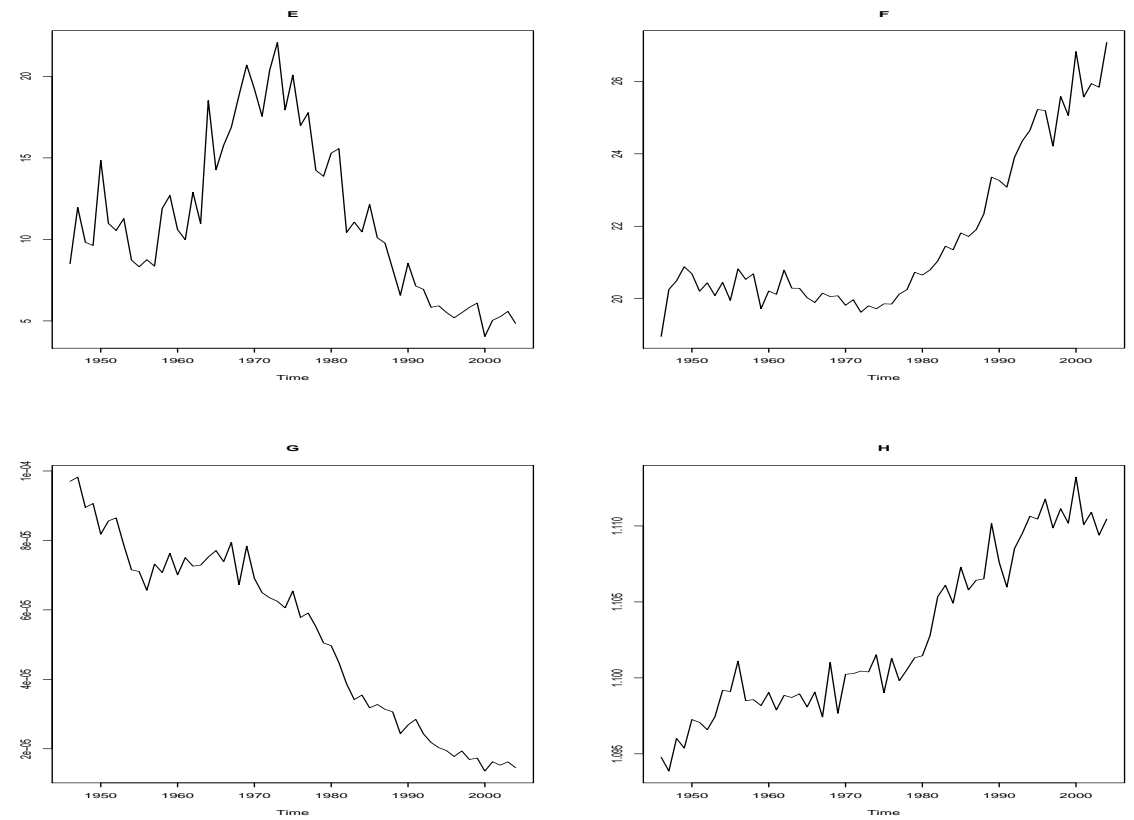

been declining, the rate of increase by age has been increasing. For females, the parameters were also estimated in a similar way (see Figure 14).

The correlation matrix of the parameters are shown in tables 9 and 10:

\begin{tabular}{rrrrrrrrr}
\hline & $\mathrm{A}$ & $\mathrm{B}$ & $\mathrm{C}$ & $\mathrm{D}$ & $\mathrm{E}$ & $\mathrm{F}$ & $\mathrm{G}$ & $\mathrm{H}$ \\
\hline $\mathrm{A}$ & 1.00 & -0.03 & 0.65 & 0.07 & 0.24 & -0.68 & 0.89 & -0.85 \\
$\mathrm{~B}$ & -0.03 & 1.00 & 0.60 & -0.17 & -0.44 & 0.37 & -0.29 & 0.32 \\
$\mathrm{C}$ & 0.65 & 0.60 & 1.00 & 0.09 & 0.05 & -0.37 & 0.51 & -0.47 \\
$\mathrm{D}$ & 0.07 & -0.17 & 0.09 & 1.00 & 0.72 & -0.55 & 0.25 & -0.29 \\
$\mathrm{E}$ & 0.24 & -0.44 & 0.05 & 0.72 & 1.00 & -0.76 & 0.57 & -0.62 \\
$\mathrm{~F}$ & -0.68 & 0.37 & -0.37 & -0.55 & -0.76 & 1.00 & -0.87 & 0.90 \\
$\mathrm{G}$ & 0.89 & -0.29 & 0.51 & 0.25 & 0.57 & -0.87 & 1.00 & -0.98 \\
$\mathrm{H}$ & -0.85 & 0.32 & -0.47 & -0.29 & -0.62 & 0.90 & -0.98 & 1.00 \\
\hline
\end{tabular}

Table 9: Male Parameters Correlation Matrix - Heligman Pollard Model and Australian Data

Unit root tests for the parameters indicate they are at most $I(1)$ with a constant and a trend.

The parameters are modeled as a stochastic system using a $\operatorname{VAR}(\mathrm{p})$. In order to improve the model fit and to ensure the parameters are positive the logs of the parameters are modeled. The diagnostic tests show that a $\operatorname{VAR}(2)$ for the logs of the parameters is adequate for both males and females.

The tests show that a VECM with one or, in the case of females, two cointegration relations is required. The parameters of the Heligman-Pollard Model when modeled as a system are affected by at least one common 

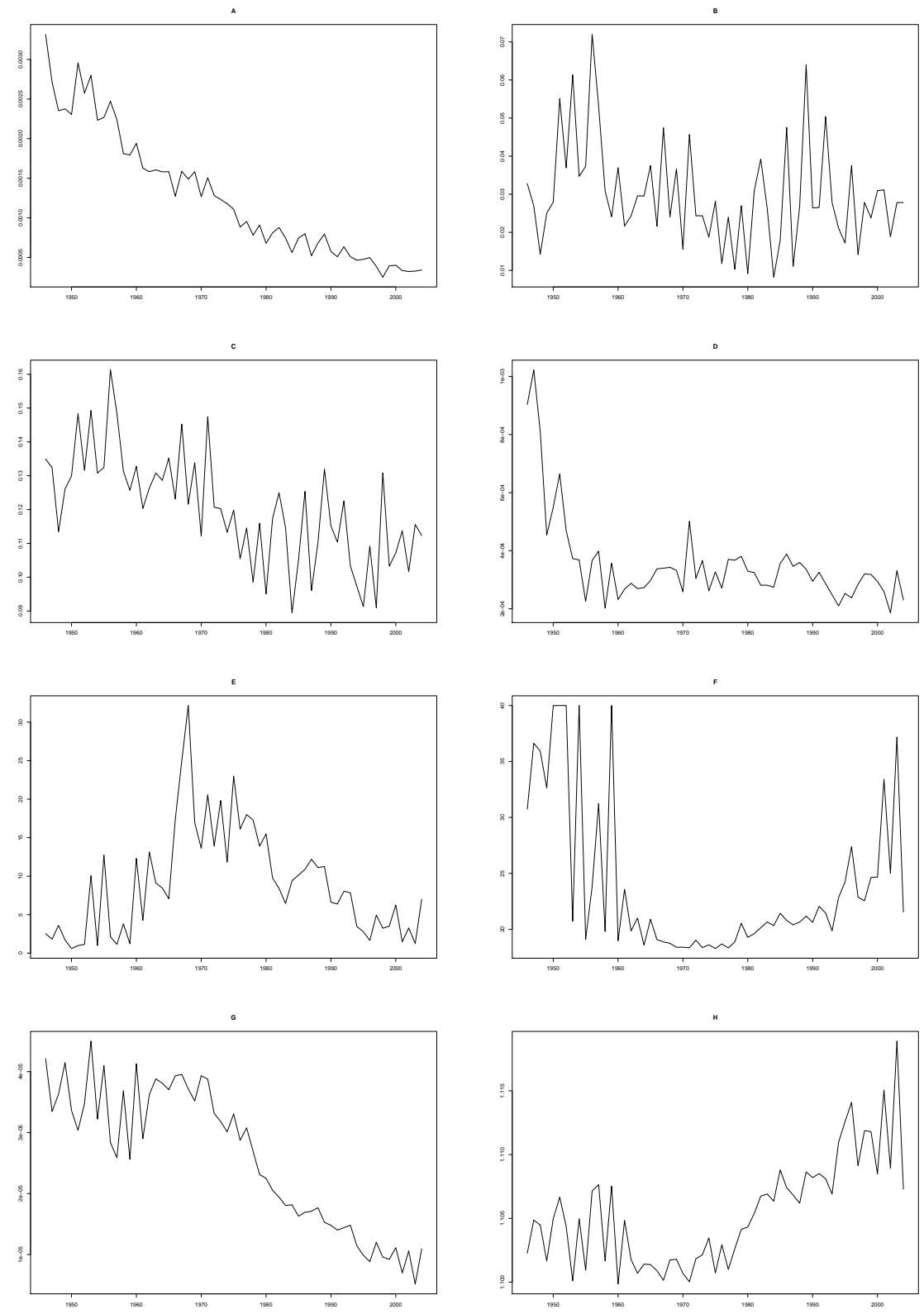

Figure 14: Female Heligman Pollard Model Parameters for Australian Data

stochastic trend.

\section{Conclusions}

This paper has presented the results of an analysis of longevity trends and volatility for a number of major countries using econometric techniques. This provides a basis for the development of country and age-based longevity risk 


\begin{tabular}{rrrrrrrrr}
\hline & $\mathrm{A}$ & $\mathrm{B}$ & $\mathrm{C}$ & $\mathrm{D}$ & $\mathrm{E}$ & $\mathrm{F}$ & $\mathrm{G}$ & $\mathrm{H}$ \\
\hline $\mathrm{A}$ & 1.00 & 0.40 & 0.73 & 0.62 & -0.13 & 0.44 & 0.80 & -0.54 \\
$\mathrm{~B}$ & 0.40 & 1.00 & 0.81 & 0.11 & -0.11 & 0.12 & 0.16 & -0.03 \\
$\mathrm{C}$ & 0.73 & 0.81 & 1.00 & 0.33 & -0.02 & 0.21 & 0.59 & -0.39 \\
$\mathrm{D}$ & 0.62 & 0.11 & 0.33 & 1.00 & -0.19 & 0.54 & 0.33 & -0.15 \\
$\mathrm{E}$ & -0.13 & -0.11 & -0.02 & -0.19 & 1.00 & -0.69 & 0.35 & -0.58 \\
$\mathrm{~F}$ & 0.44 & 0.12 & 0.21 & 0.54 & -0.69 & 1.00 & -0.04 & 0.36 \\
$\mathrm{G}$ & 0.80 & 0.16 & 0.59 & 0.33 & 0.35 & -0.04 & 1.00 & -0.90 \\
$\mathrm{H}$ & -0.54 & -0.03 & -0.39 & -0.15 & -0.58 & 0.36 & -0.90 & 1.00 \\
\hline
\end{tabular}

Table 10: Female Parameters Correlation Matrix - Heligman Pollard Model and Australian Data

models that capture trends including common trends across age, sex and country and provide a basis for assessing longevity risk in a consistent modeling framework. Stochastic common trends can be included in the Lee-Carter model consistent with a difference stationary model but the Lee-Carter model does not include sufficient random factors driving mortality changes.

Mortality rates are found to have stochastic trends for almost all ages and across all the countries in the study. This means that trends in the historical rates are stochastic and shocks are permanent. Volatility increases through time as shocks accumulate in the series. Multiple factors are driving mortality changes. The number of factors driving changes in the mortality rates is similar across the countries. More factors are required than is usually assumed in models such as the Lee-Carter model and extensions.

The single country model developed for Australia shows that within the country there are common stochastic trends across ages and that a VECM model with either one, or at most two, cointegrating relationships to capture common stochastic trends. The model allows for volatilities and correlations between the parameters and provides a relatively parsimonious structure. These models allow the quantification of the benefits of diversification in portfolios as well as a consistent framework for modeling multivariate risk factors where some of these risk factors are non-stationary and others are stationary. 


\begin{tabular}{|c|c|c|c|c|c|c|}
\hline Males & & & & & & \\
\hline ADF Test & P-Values & & & & & \\
\hline & Constant & Lags & DW Stat. & Constant, Trend & Lags & DW Stat. \\
\hline $\mathrm{A}$ & 0.2715 & 1 & 2.1829 & $0.4119^{(1)}$ & 1 & 2.1014 \\
\hline$\Delta \mathrm{A}$ & 0 & 0 & 2.1673 & 0 & 0 & 2.1973 \\
\hline B & 0 & 0 & 2.0826 & 0 & 0 & 2.0470 \\
\hline$\Delta \mathrm{B}$ & 0 & 2 & 1.9910 & 0 & 2 & 1.9938 \\
\hline $\mathrm{C}$ & 0.0530 & 1 & 2.1049 & 0 & 0 & 2.0158 \\
\hline$\Delta \mathrm{C}$ & 0 & 1 & 2.0670 & 0 & 1 & 2.0689 \\
\hline $\mathrm{D}$ & 0.3564 & 0 & 2.1215 & 0.5266 & 0 & 2.2177 \\
\hline$\Delta \mathrm{D}$ & 0 & 0 & 1.9578 & 0 & 0 & 1.9911 \\
\hline $\mathrm{E}$ & 0.8250 & 1 & 2.0747 & 0.8632 & 1 & 2.0831 \\
\hline$\Delta \mathrm{E}$ & 0 & 0 & 2.0999 & 0 & 0 & 2.1206 \\
\hline $\mathrm{F}$ & 1 & 3 & 2.0580 & 0.9826 & 3 & 2.1085 \\
\hline$\Delta \mathrm{F}$ & 0.6815 & 6 & 2.0739 & 0 & 2 & 2.1222 \\
\hline G & 0.7406 & 1 & 1.7964 & 0.8126 & 1 & 1.7704 \\
\hline$\Delta \mathrm{G}$ & 0 & 0 & 1.7906 & 0 & 0 & 1.7979 \\
\hline $\mathrm{H}$ & 0.7756 & 1 & 1.9960 & 0.6150 & 1 & 1.9278 \\
\hline$\Delta \mathrm{H}$ & 0 & 0 & 2.0012 & 0 & 0 & 2.0041 \\
\hline Females & & & & & & \\
\hline ADF Test & P-Values & & & & & \\
\hline & Constant & Lags & DW Stat. & Constant, Trend & Lags & DW Stat. \\
\hline $\mathrm{A}$ & 0.5885 & 4 & 1.5817 & 0.9710 & 4 & 1.5756 \\
\hline$\Delta \mathrm{A}$ & 0 & 3 & 1.5772 & 0 & 3 & 1.5864 \\
\hline B & 0 & 0 & 2.0231 & 0 & 0 & 2.0034 \\
\hline$\Delta \mathrm{B}$ & 0 & 2 & 1.9133 & 0 & 2 & 1.9149 \\
\hline $\mathrm{C}$ & 0.0955 & 1 & 2.1297 & 0 & 0 & 1.9960 \\
\hline$\Delta \mathrm{C}$ & 0 & 2 & 1.9556 & 0 & 2 & 1.9555 \\
\hline $\mathrm{D}$ & 0 & 1 & 2.4196 & 0.0075 & 0 & 2.3638 \\
\hline$\Delta \mathrm{D}$ & 0 & 0 & 2.0061 & 0 & 0 & 2.0797 \\
\hline $\mathrm{E}$ & 0.2784 & 1 & 1.9165 & $0.2689^{(2)}$ & 1 & 1.9389 \\
\hline$\Delta \mathrm{E}$ & 0 & 0 & 1.9589 & 0 & 0 & 1.9582 \\
\hline $\mathrm{F}$ & 0.9540 & 10 & 1.7405 & 0.6648 & 5 & 2.3690 \\
\hline$\Delta \mathrm{F}$ & 0.2343 & 9 & 1.7404 & 0 & 4 & 2.3124 \\
\hline $\bar{G}$ & 0.8861 & 1 & 2.3407 & 0.3957 & 1 & 2.2482 \\
\hline$\Delta \mathrm{G}$ & 0 & 0 & 2.3612 & 0 & 1 & 1.9383 \\
\hline $\mathrm{H}$ & 0.8189 & 1 & 2.2398 & 0.5102 & 1 & 2.1932 \\
\hline$\Delta \mathrm{H}$ & 0 & 0 & 2.2851 & 0 & 1 & 1.9441 \\
\hline
\end{tabular}

Table 11: Unit Root Tests on Male and Female Heligman-Pollard Parameters 1946-2004 (1) Significant Trend in Unit Root Test. (2) No constant and No Trend. 


\begin{tabular}{lc|c}
\hline & Males & Females \\
\cline { 2 - 3 } VAR $(1)$ \\
\hline Portmanteau Test & 0.2793 & 0.9930 \\
\hline Jarque-Bera Test & 0.0720 & 0.0260 \\
\hline & \multicolumn{2}{c}{ VAR $(2)$} \\
\hline Portmanteau Test & 0.9560 & 0.9906 \\
\hline Jarque-Bera Test & 0.1139 & 0.8533 \\
\hline
\end{tabular}

Table 12: Diagnostic tests for VAR(p) model for Heligman-Pollard parameters

\begin{tabular}{rrrrr}
\hline $\mathrm{H}_{0}$ & Test & $10 \mathrm{pct}$ & $5 \mathrm{pct}$ & $1 \mathrm{pct}$ \\
\hline $\mathrm{r}<=7$ & 0.11 & 6.50 & 8.18 & 11.65 \\
$\mathrm{r}<=6$ & 6.99 & 12.91 & 14.90 & 19.19 \\
$\mathrm{r}<=5$ & 9.70 & 18.90 & 21.07 & 25.75 \\
$\mathrm{r}<=4$ & 15.73 & 24.78 & 27.14 & 32.14 \\
$\mathrm{r}<=3$ & 19.11 & 30.84 & 33.32 & 38.78 \\
$\mathrm{r}<=2$ & 30.16 & 36.25 & 39.43 & 44.59 \\
$\mathrm{r}<=1$ & 43.46 & 42.06 & 44.91 & 51.30 \\
$\mathrm{r}=0$ & 56.48 & 48.43 & 51.07 & 57.07 \\
\hline
\end{tabular}

Table 13: Tests for cointegration for Heligman-Pollard parameters -Male

\begin{tabular}{rrrrr}
\hline $\mathrm{H}_{0}:$ & Test & $10 \mathrm{pct}$ & $5 \mathrm{pct}$ & $1 \mathrm{pct}$ \\
\hline $\mathrm{r}<=7$ & 0.38 & 6.50 & 8.18 & 11.65 \\
$\mathrm{r}<=6$ & 9.34 & 12.91 & 14.90 & 19.19 \\
$\mathrm{r}<=5$ & 14.18 & 18.90 & 21.07 & 25.75 \\
$\mathrm{r}<=4$ & 22.03 & 24.78 & 27.14 & 32.14 \\
$\mathrm{r}<=3$ & 23.94 & 30.84 & 33.32 & 38.78 \\
$\mathrm{r}<=2$ & 28.66 & 36.25 & 39.43 & 44.59 \\
$\mathrm{r}<=1$ & 47.75 & 42.06 & 44.91 & 51.30 \\
$\mathrm{r}=0$ & 63.02 & 48.43 & 51.07 & 57.07 \\
\hline
\end{tabular}

Table 14: Tests for cointegration for Heligman-Pollard parameters -Female 


\section{References}

[1] Alho, J.M., Discussion of Lee (2000). North American Actuarial Journal, 2000. 4: p. 91-93.

[2] Booth, H., Applying Lee-Carter under conditions of variable mortality decline. Population Studies, 2002. 56(3).

[3] Booth, H., et al., Lee-Carter Mortality Forecasting: A Multi-Country Comparison of Variants and Extensions. Demographic Research, 2006. 15(9): p. 289-310.

[4] Brouhns, N., M. Denuit, and J.K. Vermunt, A Poisson Log-Bilinear Regression Approach to the Construction of Projected Life Tables." Insurance: Mathematics and Economics, 2002. 31: p. 373-393.

[5] Byers, J.D. and D.A. Peel, Some Evidence on the Interdependence of National Stock Markets and the Gains from International Portfolio Diversification. Applied Financial Economics, 1993. 3(3): p. 239-242.

[6] Chan, W.-S., S.-H. Li, and S.-H. Cheung. Testing Deterministic versus Stochastic Trends in the Lee-Carter Mortality Indexes and Its Implications for Projecting Mortality Improvements at Advanced Ages. in Living to 100 and Beyond Symposium. 2008. Orlando, Fla.: Society of Actuaries.

[7] Chan, N.H., ed. Time Series: Application to Finance. Probability and Statistics, ed. Wiley. 2002, John Wiley

[8] Darkiewicz, G. and T. Hoedemakers, How the Cointegration Analysis Can Help in Mortality Forecasting, in K.U.Leuven Host Document: DTEW Research Report 2004, K.U.Leuven. p. $1-24$.

[9] DeJong, D.N., et al., Integration versus Trend Stationary in Time Series. Econometrica, 1992. 60(2): p. 423-433.

[10] Denton, F.T., C.H. Feaver, and B.G. Spencer, Time series analysis and Stochastic Forecasting: An econometric study of mortality and life expectancy. Journal of Population Economics, 2005. 18: p. 203-227.

[11] Dickey, D.A. and W.A. Fuller, Distribution of the Estimators for Autoregressive Time Series with a Unit Root, Journal of the American Statistical Association, 1979, 74, p. 427431.

[12] Engle, R.F. and C.W.J. Granger, Cointegration and error-correction: Representation, estimation and testing. Econometrica 1987. 55: p. 251-276.

[13] Granger, C.W.J. and P. Newbold, Spurious regressions in econometrics. Journal of Econometrics 1974. 2: p. 111-120.

[14] Hanewald, K., Mortality Modeling: Lee-Carter and the Macroeconomy(January 16, 2009). SFB 649 Discussion Paper 2009-008. Available at SSRN: http://ssrn.com/abstract=1336888

[15] Hartmann, M., Past and recent attempts to model mortality at all ages. Journal of Official Statistics, 1987. 3: p. 19-36.

[16] Harvey, A. C., Forecasting, Structural Time Series Models and the Kalman Filter. 1991.

[17] Heligman, L. and J. Pollard, The age pattern of mortality. Journal of the Institute of Actuaries, 1980. 107: p. 49-80.

[18] Hotelling, H., Analysis of a complex Statistical Variable with Principal Components. Journal of Educational Psychology, 1933. p. 417-441. 
[19] Hyndman, R.J. and M. Shahid Ullah, Robust forecasting of mortality and fertility rates: A functional data approach. Computational Statistics and

[20] Juselius, K., The Integrated VAR Model: Methodology and Applications. Advanced Texts in Econometrics, New York: Oxford University Press, 2006.

[21] Lazar, D., On forecasting mortality using the Lee-Carter model. in 3rd Conference in Actuarial Science \& Finance in Samos, 2004.

[22] Lee, R., The Lee-Carter Method for Forecasting Mortality with Various Extensions and Applications. North American Actuarial Journal, 2000. 4(80-93).

[23] Lee, R. and T. Miller, Evaluating the performance of the Lee-Carter method for forecasting mortality. Demography, 2001. 38(4): p. 537.

[24] Lee, R.D. and L.R. Carter, Modeling and Forecasting U. S. Mortality. Journal of the American Statistical Association, 1992. 87: p. 659-675.

[25] Martin, F Moscoso del Prado, A Theory of Reaction Time Distributions, 2008, Working paper http://cogprints.org/6310/1/recinormal.pdf .

[26] Martinez, W. and A. Martinez, eds. Exploratory Data Analysis with MATLAB. ed. C. HALL/CRC. 2005, Chapman and Hall/CRC: Boca Raton.

[27] McNown, R. and A. Rogers, Forecasting Mortality: A Parameterized Time Series Approach. Demography, 1989. 26(4): p. 645-660.

[28] Pagan, A. and H.M. Pesaran, Econometric Analysis of Structural Systems with Permanent and Transitory Shocks, in Australian School of Business Research Papers. 2008, University of New South Wales: Sydney

[29] Pfaff, B., VAR, SVAR and SVEC Models: Implementation with the R Package vars. Journal of Statistical Software, 2008. 27(4).

[30] Pitacco, E., Mortality and Longevity: A Risk Management Perspective, in IAA Life Colloquium. 2007: Stockholm.

[31] Phillips, P. C. B., Perron, P., Testing for a unit root in time series regression. Biometrika, 1988, 75335346 .

[32] Triacca,U., Cointegration in the VAR(1) process: Characterization and Testing. Statistical Papers, 2002, 43 435-443.

[33] Tuljapurkar, S. and C. Boe, Mortality Change and forecasting: How much and how little do we know? North American Actuarial Journal, 1998. 2(4): p.

[34] Tuljapurkar, S., N. Li, and C. Boe, A universal pattern of mortality decline in the G 7 countries. Nature, 2000. 405: p. 789-792.

[35] Tuljarpurkar, S., Forecasting mortality change: Questions and Assumptions. North American Actuarial Journal, 1998. 2(4): p. 127-134.

[36] Wills, S. and Sherris, M., Integrating Financial and Demographic Longevity Risk Models: An Australian Model for Financial Applications 2008, UNSW Australian School of Business

[37] Wong-Fupuy, C. and S. Haberman, Projecting Mortality Trends: Recent Developments in the United Kingdom and the United States. North American Actuarial Journal, 2004. 8(2): p. $56-83$. 